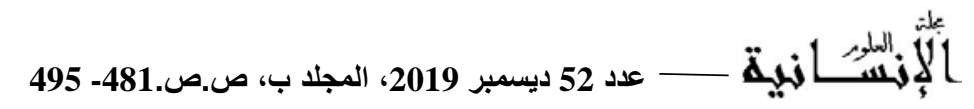

\title{
العلاقة بين المناولة والمسؤولية الاجتماعية للمؤسسات الاقتصادية
}

The relation between outsourcing and corporate social responsibility

تاريخ الاستلام : 2019/10/28 ؛ تاريخ القبول : 2019/11/21

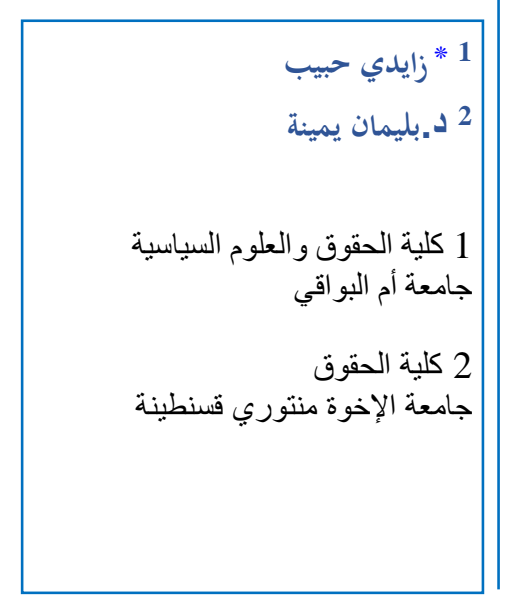

Abstract

Social responsibility of the economic enterprises on the basis of the introduction of the interests of the stakeholders in these strategies, that is to say all the activities of the company and their relations with stakeholders in subcontractors; Outsourcing is a mechanism according to the companies. This relationship between two companies can bring several benefits if respect for ethics and the win-win principle; that's what we call the socially responsible subcontracting which participated in the development of the industrial and economic fabric and which has promoted the national product.

Keywords: Outsourcing, social responsibility, small and medium sized enterprise SME, socially responsible subcontracting, promoting the national product.

\section{Résumé}

La responsabilité sociétale des entreprises économiques se base sur l'introduction des intérêts des parties prenantes dans ses stratégies, ceci couvre l'ensemble des activités de l'entreprise et leur relations avec les parties prenantes dont les soustraitants ;

La sous-traitance est un mécanisme selon lequel des entreprises généralement moin importantes prennent en charge une parties des activités d'une entreprise plus grande car souvent les sous-traitants sont des PME; Cette relation entre deux entreprises peut engendrer plusieurs avantages si le respect des éthiques et le principe gagnant-gagnant c'est ce qu'on appelle la sous-traitance socialement responsable. Elle contribue également au développement du tissu industriel du pays et la promotion du produit nationale.

Mots clés: la sous-traitance, la responsabilité sociale, petites et moyennes entreprises PME, la sous-traitance socialement responsable, la promotion du produit nationale.

* Corresponding author, e-mail: zaidihabib72@gmail.com 


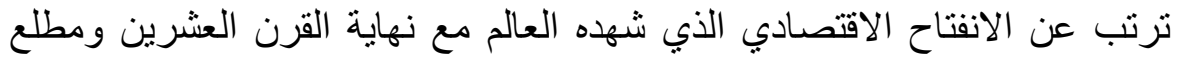

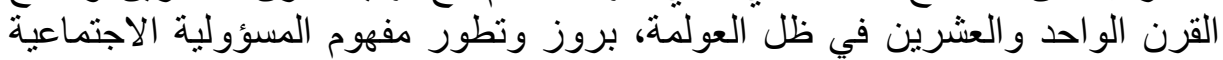

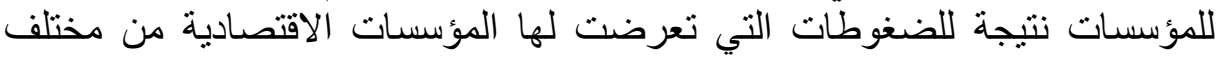

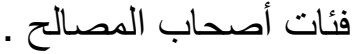
والجزائر بدورها سعت إلى تحقيق الانفتاح الاقتصادي وكذا تدعيم المؤسسات و المنتوج الوطني وهذا ما تم تكريسه بموجب الفقرة الثانية من المادة 43 المستحدثة بموجب التعديل الدستوري لسنة 2016 والتي ورد فيهارتعمل الدولة على تحسين مناخ الأعمال وتشجيع ازدهار المؤسسات دون تمييز خدمة للتنمية الاقتصادية الوطنية《(1).

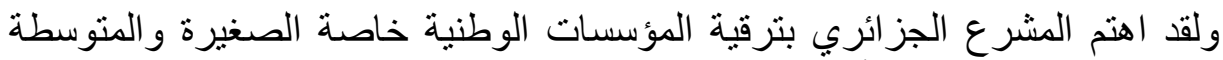

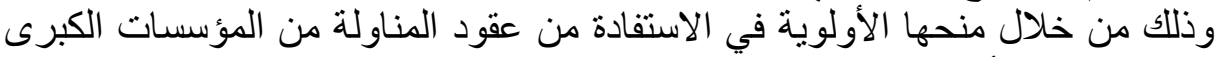

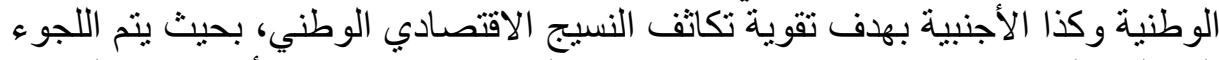
إلى المناولة في مجالات اقتصادية متنوعة إذ لها مفهوم أقتصادي أوسع من الألفي المفهوم

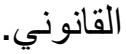
فالمناولة الصناعية ترتكز بالنسبة للمؤسسة الاقتصادية على الاستعانة بمؤسسات

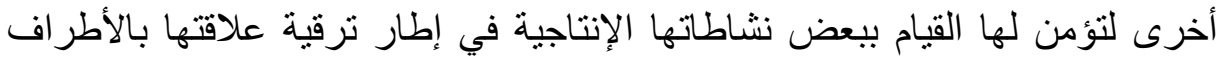

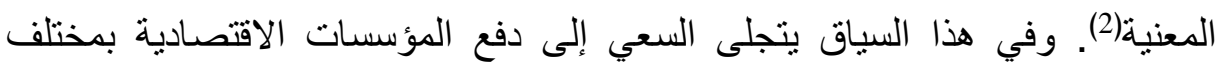

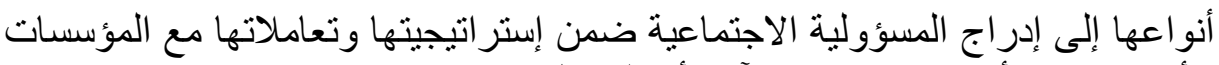

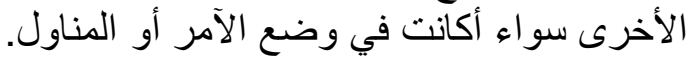

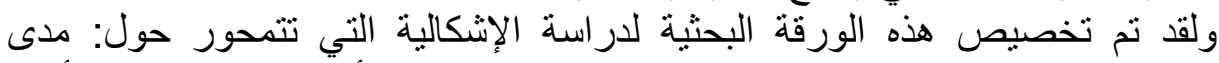

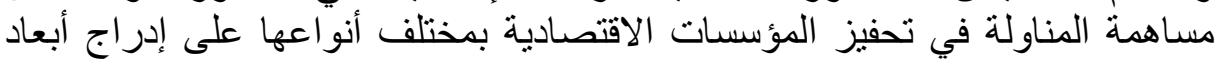
المسؤولية الاجتماعية ضمن إستر اتيجيتها؟

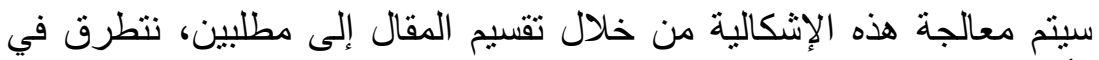

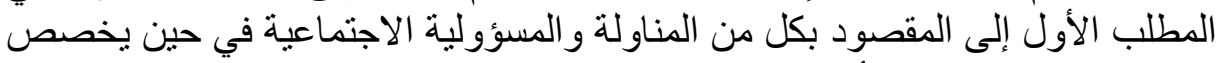
المطلب الثاني لدراسة النأثنير المتبادل بينهما.

المطلب الأول: المقصود بكل من المناولة والمسؤولية الاجتماعية للمؤسسات

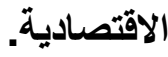
تعد كل من المناولة والمسؤولية الاجتماعية للمؤسسات الاقتصادية فكرتين

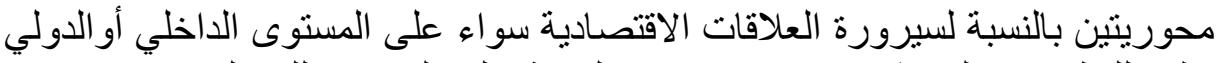

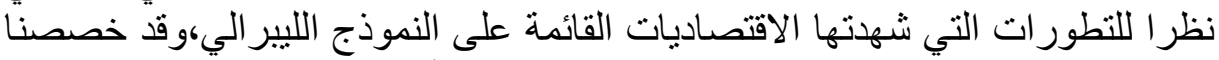

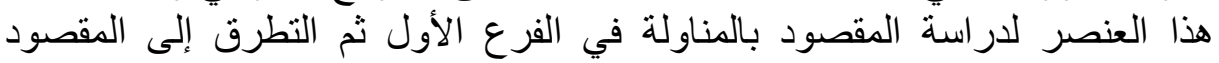
بالمسؤولية الاجتماعية في الفرعة الفوع الثاني. الفرع الأول:المقصود بالآمناولية.

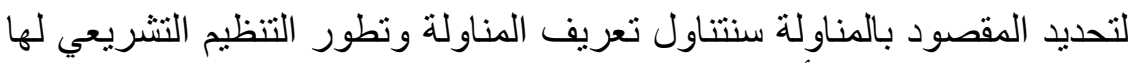

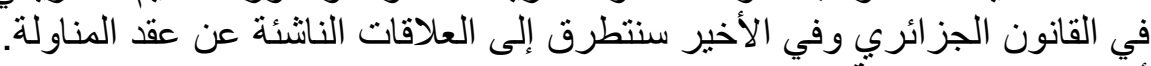

أولا: تعريف المناون الجزانئة

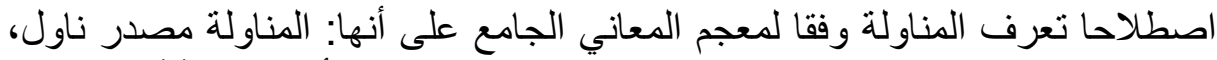

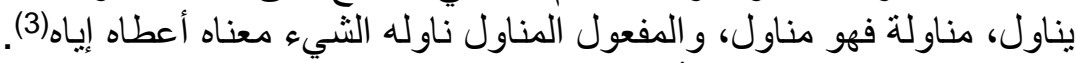

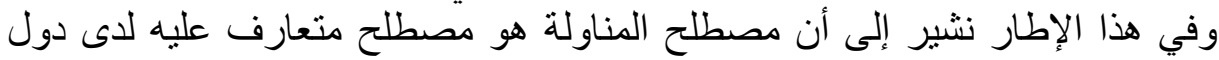


المغرب العربي وشمال إفريقيا، أما بالنسبة لدول المشرق العربي فإن المصطلح المتعارف عليه هو المقاولة من الباطن.

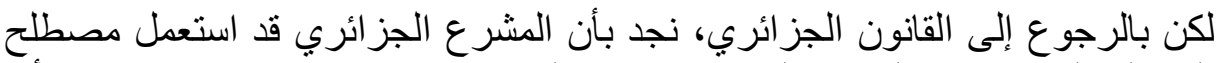

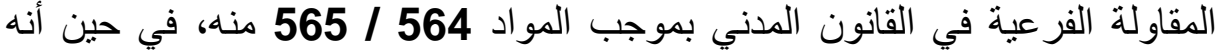

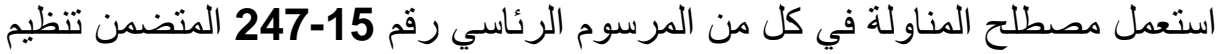

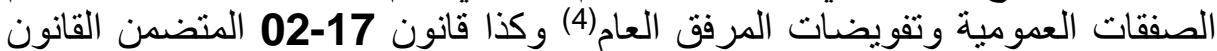

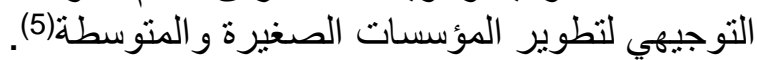

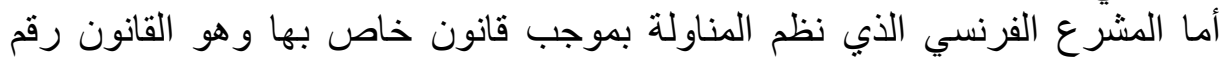

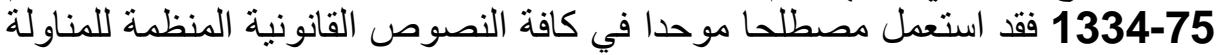

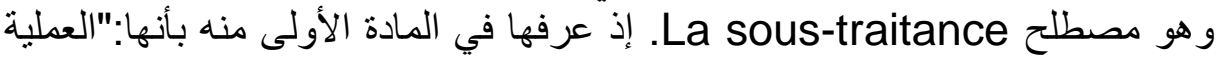

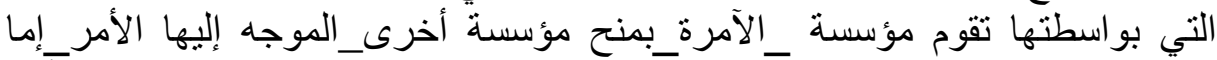

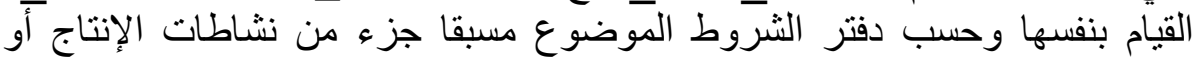

الخدمات وتحتفظ بمسؤوليتها الاقتصادية المتعلقة بإنهاء المشروع".

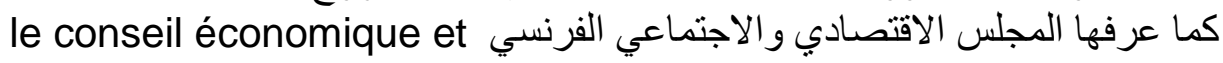
Sبكونها: Social

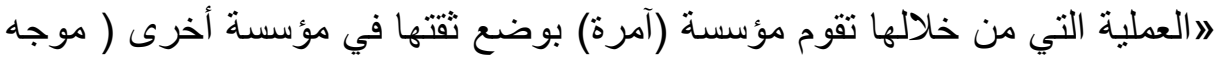
إليها الأمر/الّناولة) بتنفيذ جزء من من نشاطات الإنتاج أوتقديم الخدمات وفئات وفقا لدفتر شروط معد مسبقا وتحت مسؤوليتهاءه (7).

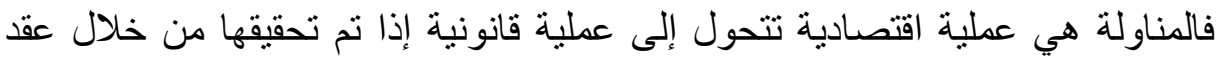

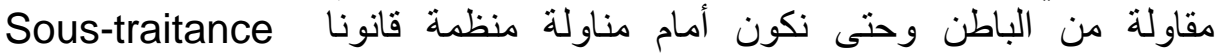
réglementée الشرط الأول: أن يكون العقد من الباطن من نفس طبرط العبيعة العقد الأصلي. الشرط الثاني: أن يكون العقد الأصلي عقد مقاولة العة أوصفقة من عمومية.

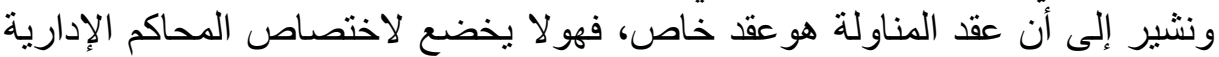

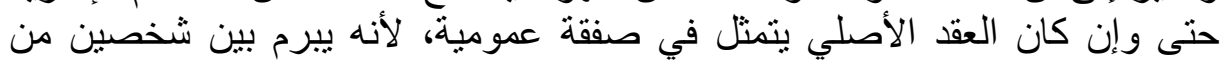
القانون الخاص وان (9). في حين أن المشرع الجزائري لم يعرف المناولة في النصوص القانونية المنظمة لها

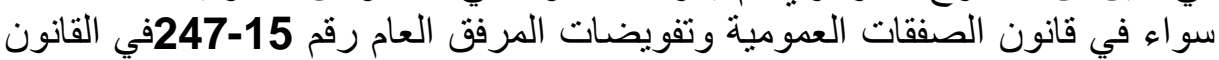

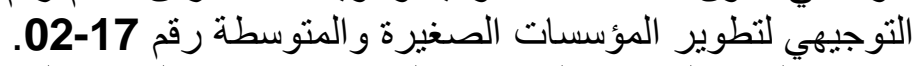

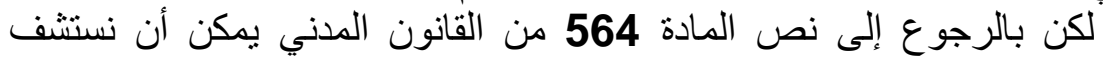

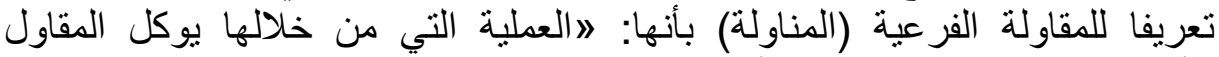

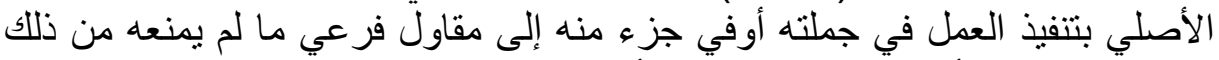

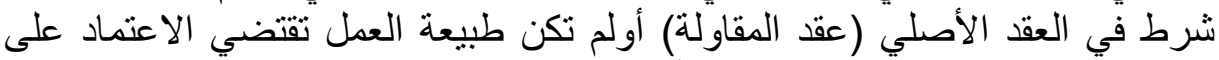

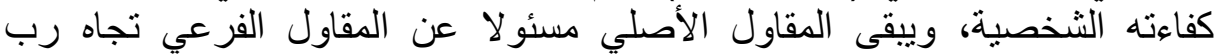

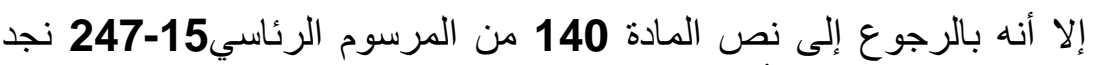

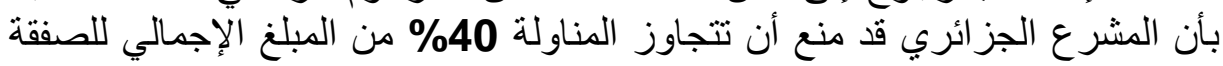
فمن هذه التعاريف نستتتج أن عقد المناولة تنشأ عنه عدة علاقات تنتج عنها

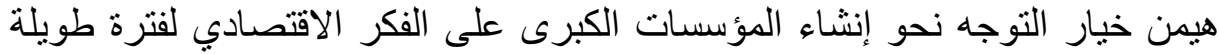

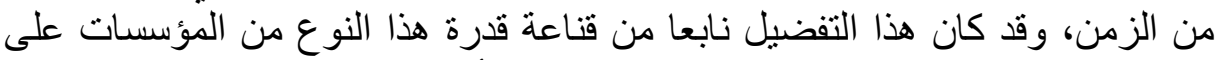

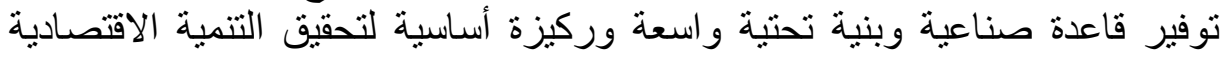
و الاجتماعية(10)،وظلت المؤسسات الاقتصادية الكبرى تعتمد على نفسها بصفة أسية كلية في 
انجاز المشاريع، إذ أنها كانت تقوم بصناعة المواد الأولية وقيامها بكامل عملية

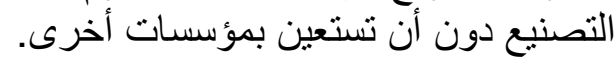

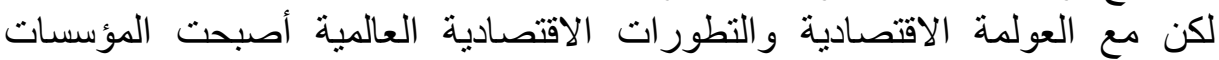

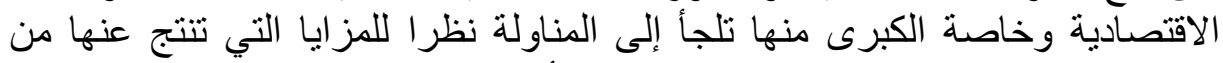

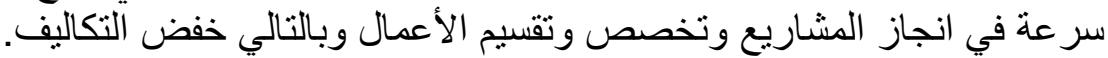

وبالنسبة للجزائر لم يكن هناك الهن التمام كبير بالمناولة إلى غاية سنة 1988

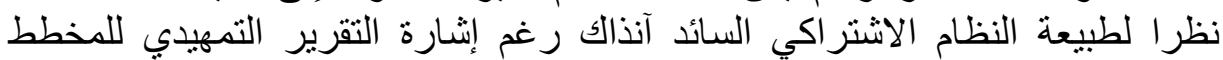

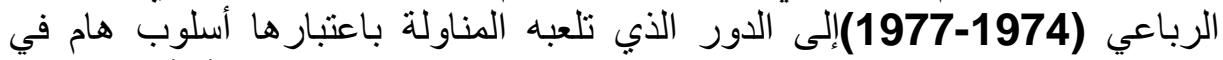

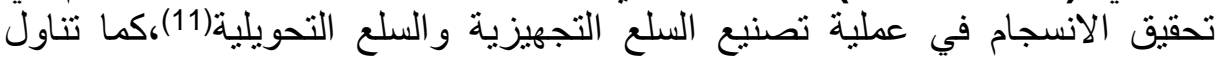

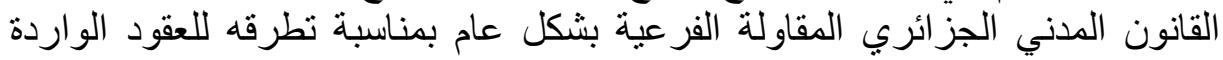

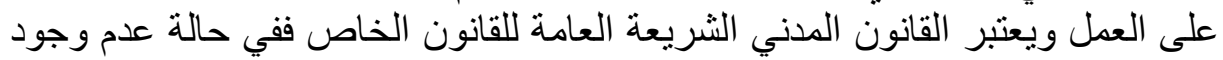
نص في القوانين الخاصة و القانون التجاري تتظم الإشكاليات القانونية المطروحة القانية

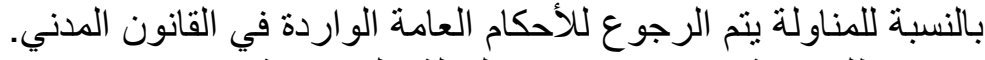

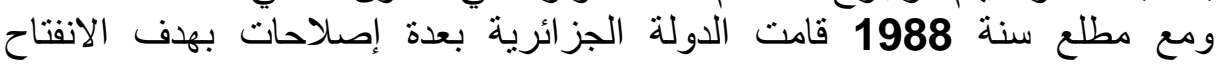

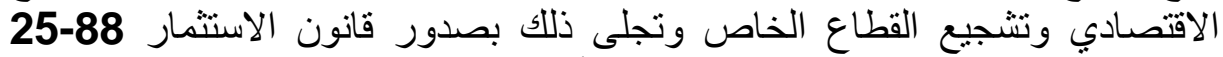

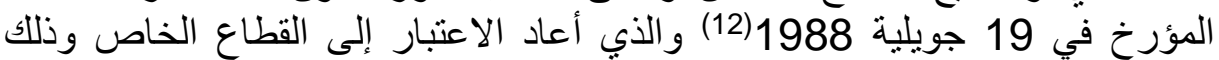

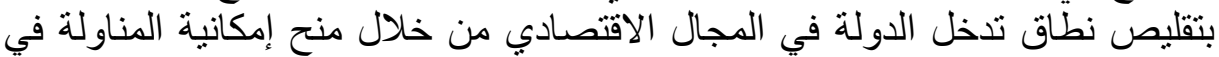

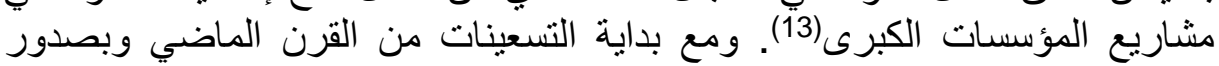
قانون الصفقات العمومية رقم

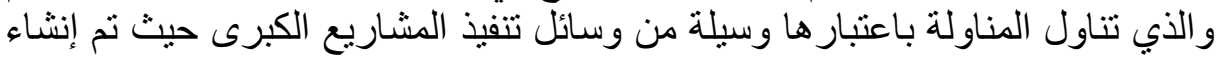

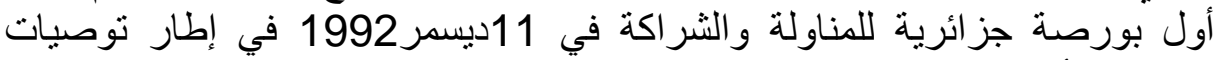

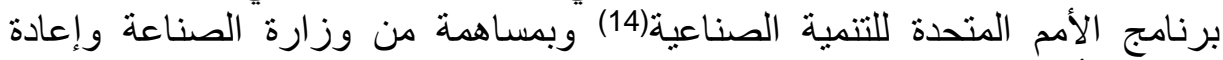

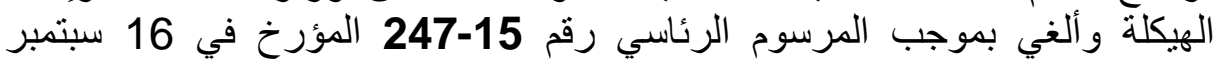
2015 المتضمن تنظيم الصفقات العمومية وتفويضات المرفق العام. الذئي نظم المناولة بموجب المواد 145-142-141-140-145 منها. كما أن القانون رقم 18-01 المؤرخ في 12 ديسمبر 141-145 دئه 2001 و المتضمن للقانون

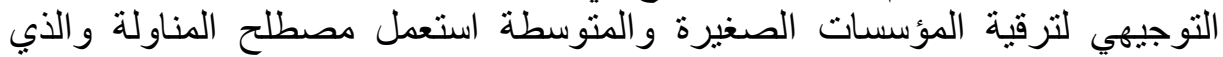

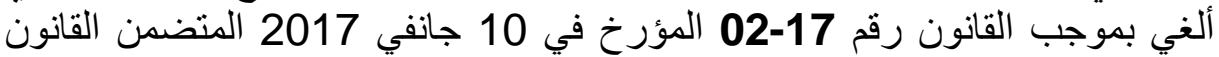

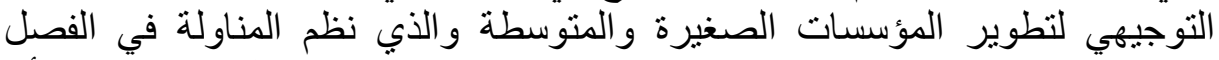

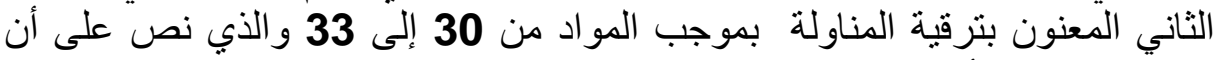
المناولة تعتبر الأداة المفضلة لتكثيف نسيج المؤسسات الصغيرة الصنية والمتوسطة وتعزيز

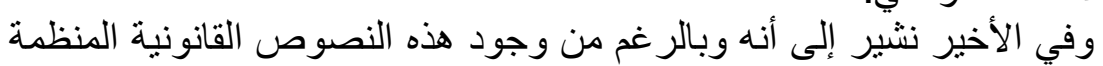
تنافسية الاقتصاد الوطني.

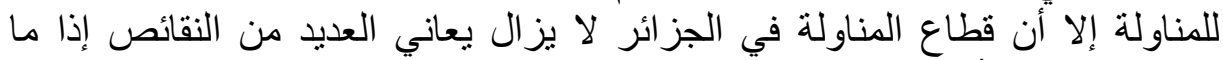

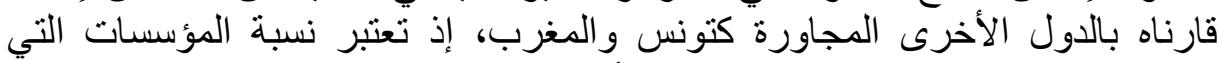

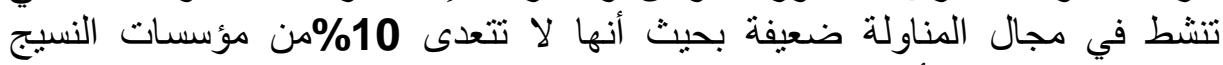

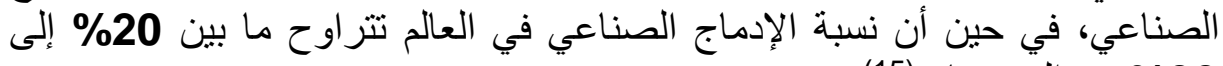

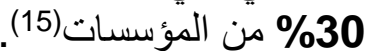

ثالثا: العلاقات الناشئة عن عقد المنات (15) عناولة.

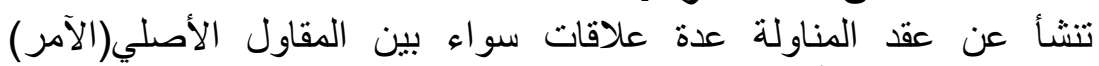

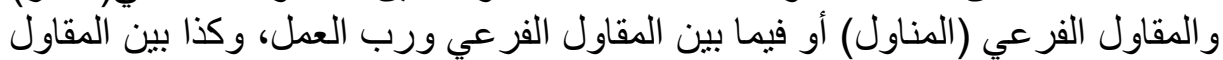

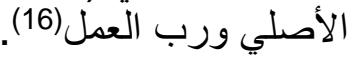


العلاقة الأولى: تكون بين المقاول الأصلي والمقاول الفرعي.

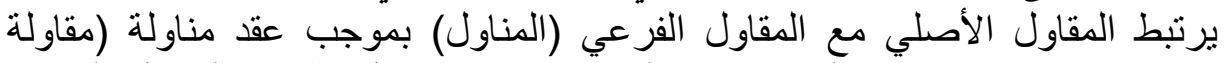

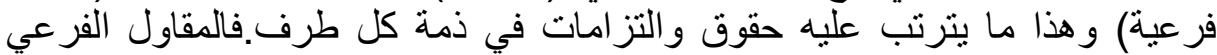

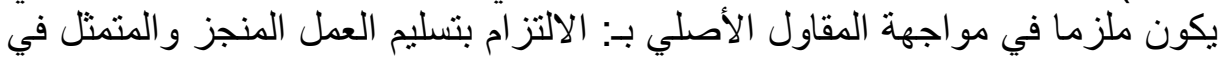
محل عقد المناولة في الميعاد المتفق عليه(17).

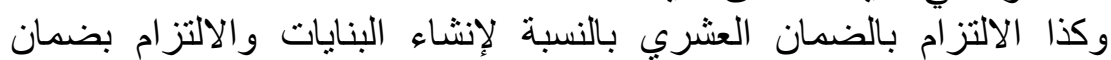

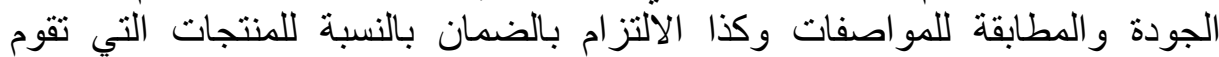
بإنتاجها لفائدة المؤسسة الآمرة بموجة المبات عقد المناولة الصناعية.

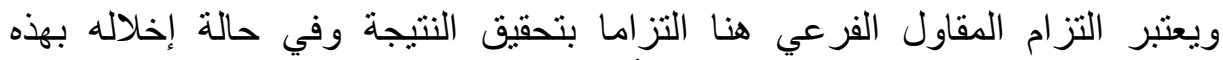

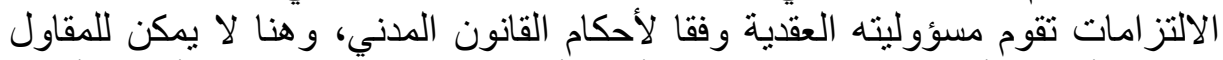

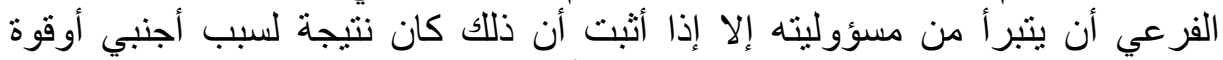

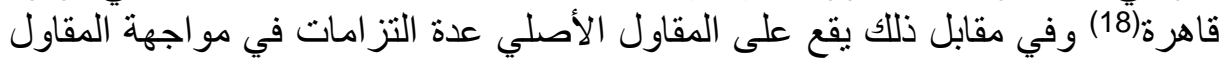
الفرعي و التي تنتئل في (19): ـ - الالتزام بدفع الأجر المتفق عليه وبالكيفية المتفق عليها، وفي حالة فسخ عقد الإل المناولة بعد البدء في الإنجاز لأي سبب كان يجوز لإنيف للمقاول أن يطالب المقاول

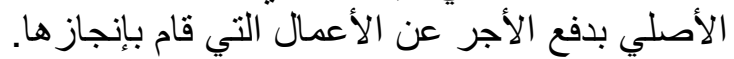

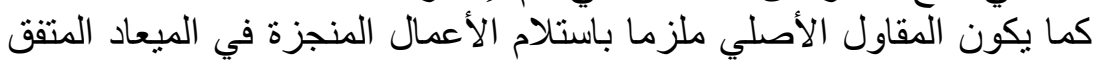

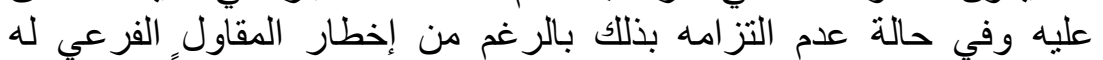

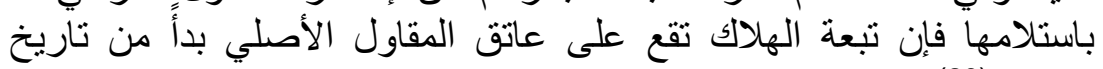
إخطار (20)

\section{العلاقة الثانية: علاقة المقاول الفرعي ورب العمل.}

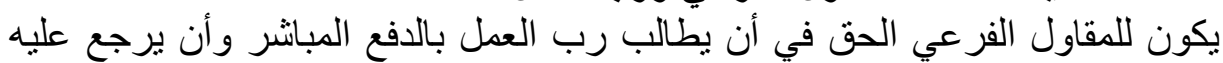

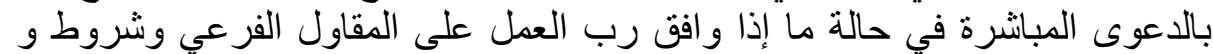

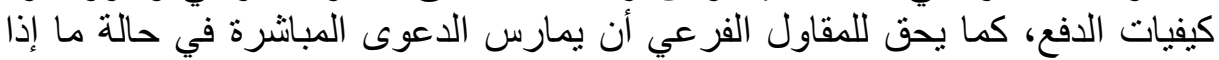

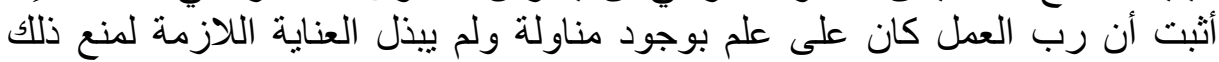

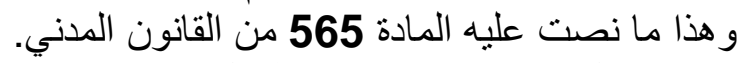

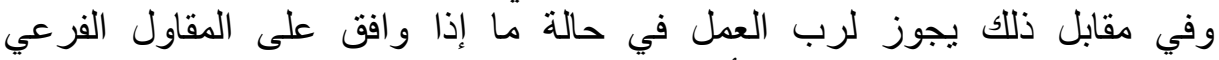

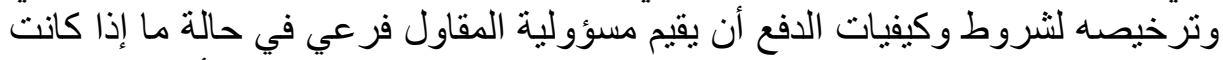

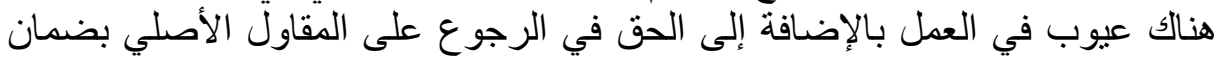

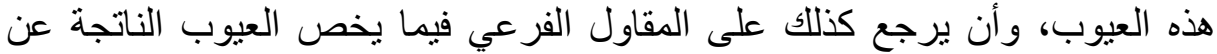

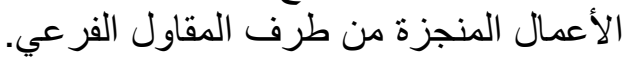

ولقد ألزمت المادة 142 من قالنون الصفارل الصفيقات العمومية وتفويضات المرفق العام

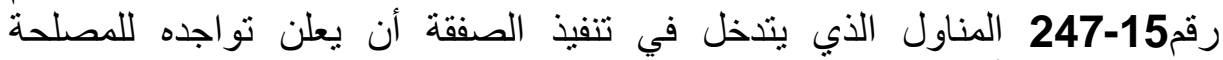

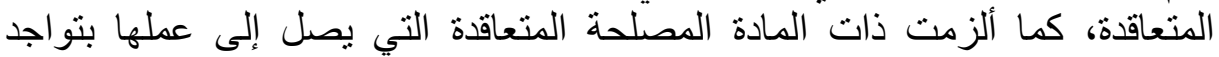

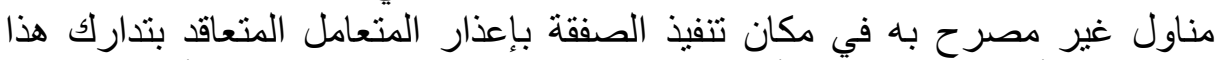

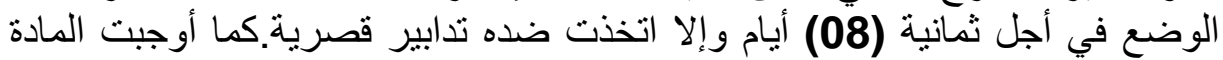

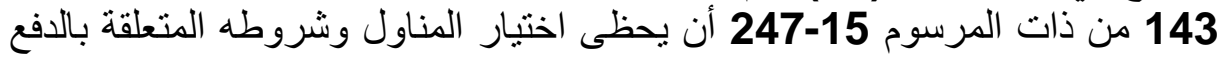
من طرف المتعامل المتعاقد وجوبا بمو افقة الماف المصلحة المتعاقدة كتابيا.

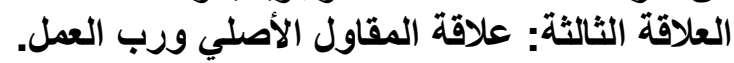
وأخير ا فيما يخص علافة علاقة المقاول الاصلي ورل الأصلي ورب العل العمل، فإن المقاول الأصلي

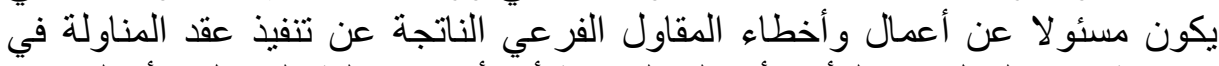

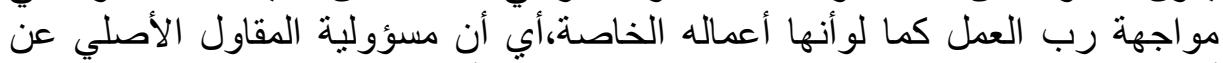

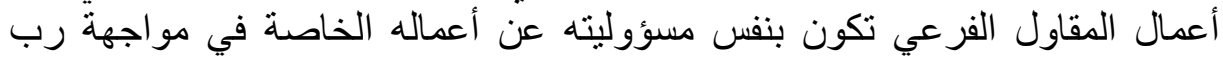

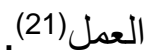


الفرع الثاني:المقصود بالمسؤولية الاجتماعية للمؤسسات الاقتصادية.

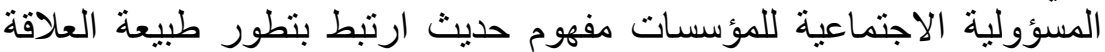

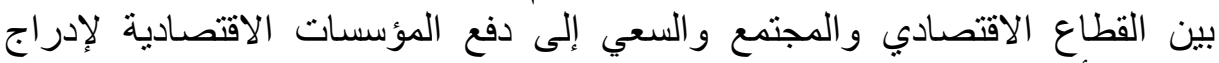

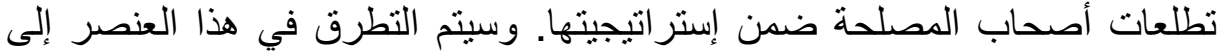
ظهور هذه المسؤولية وتعريفها. أولا: ظهور المسؤولية الاجتماعية للمؤسئات العات الاقتصادية.

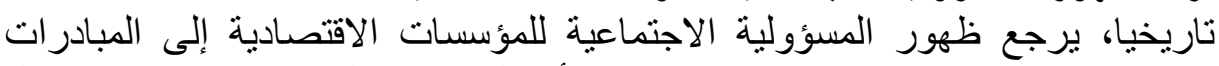

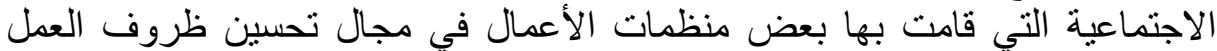

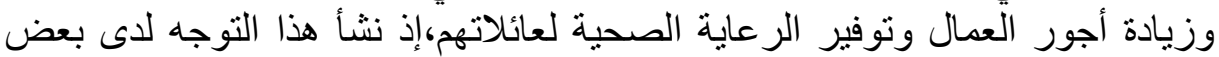

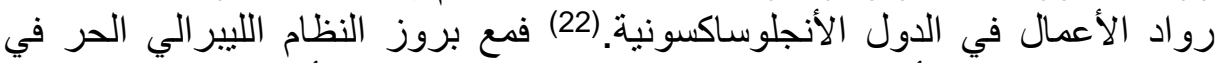

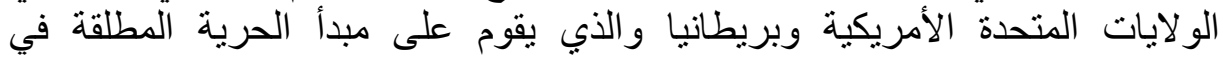

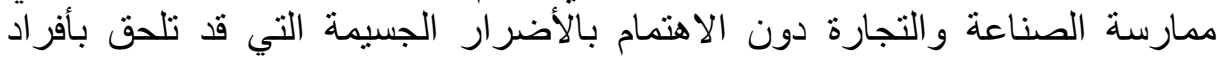

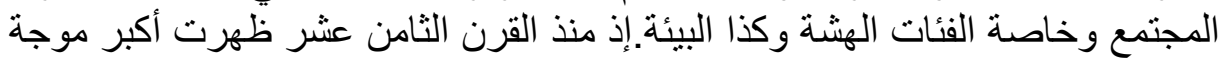

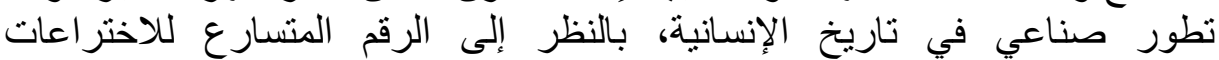

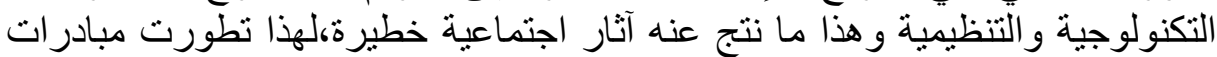

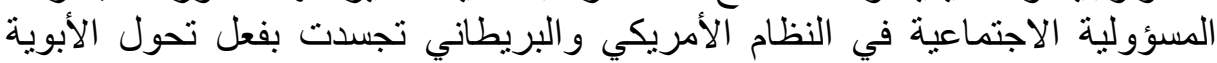

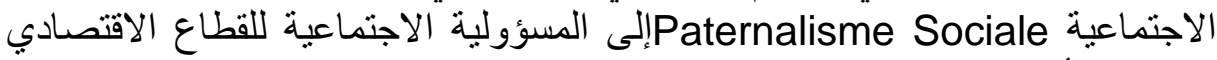

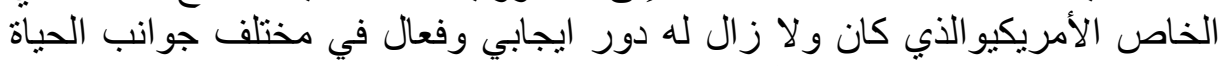

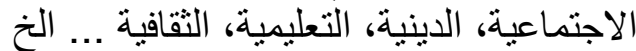

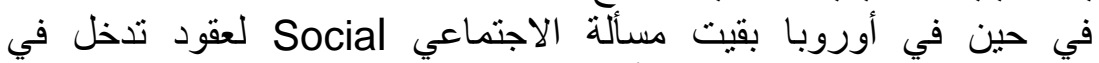

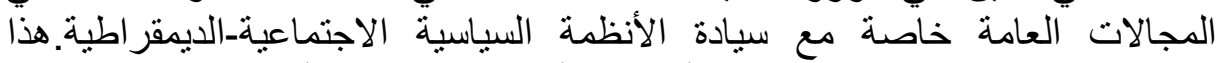

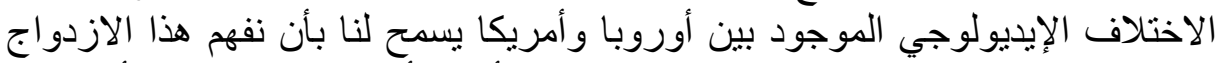

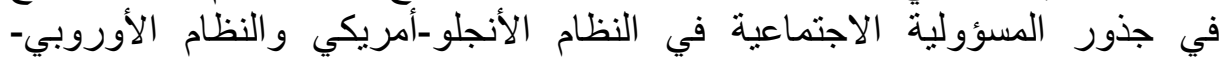

فرجال الأعمال الأمريكيين استفادوا من شرعية التدخل في مختلف مجالات الأعمال

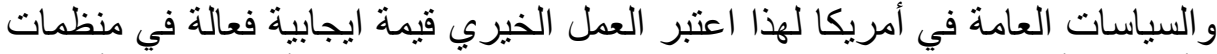

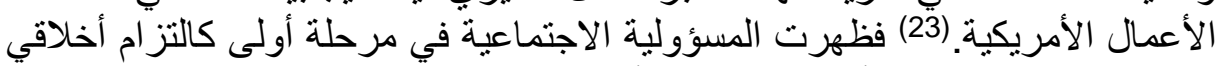

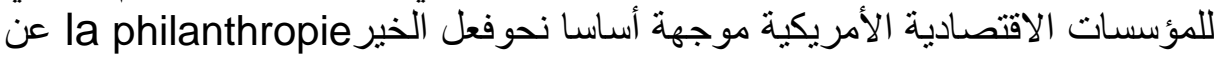

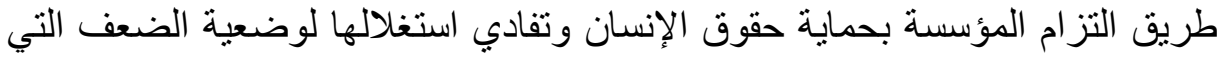
تعاني منها الفئات الثغيلة(24)

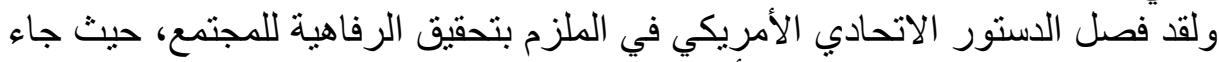

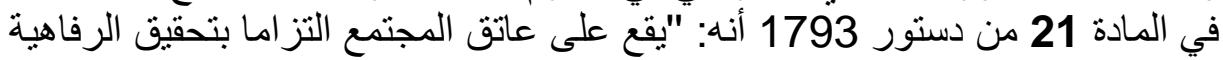

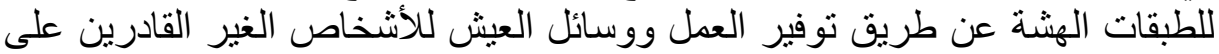

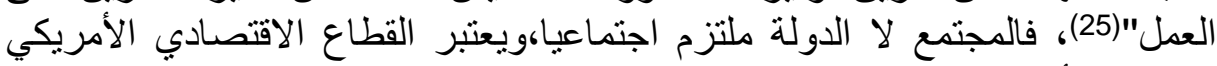

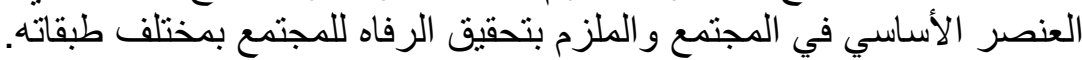

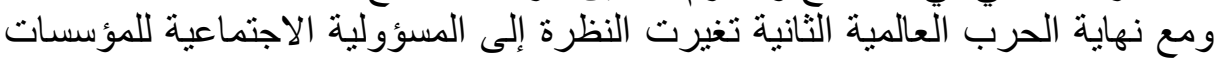

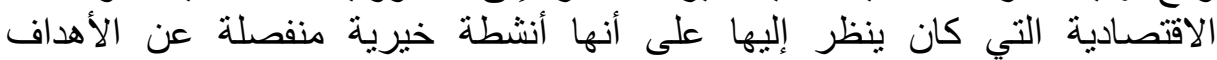

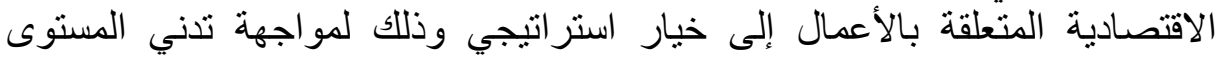

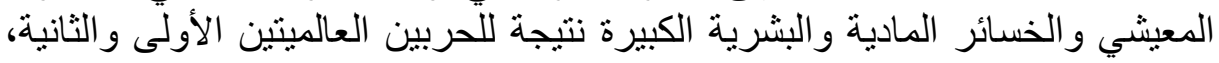

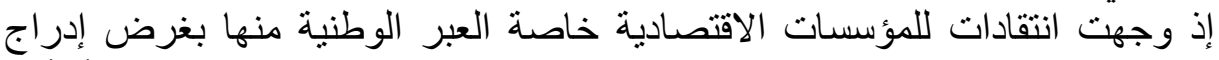

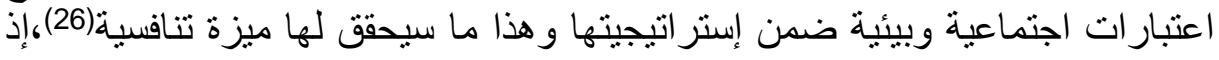

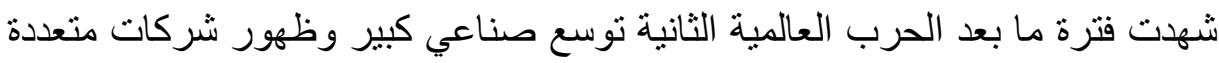


الجنسيات تسعى إلى تحقيق أكبر قدر من الأرباح وتوظيف الآلاف من العمال وتقوم

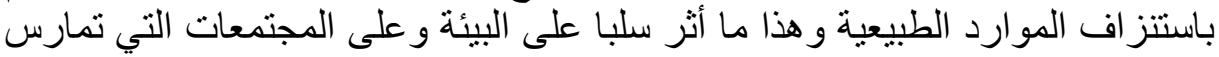

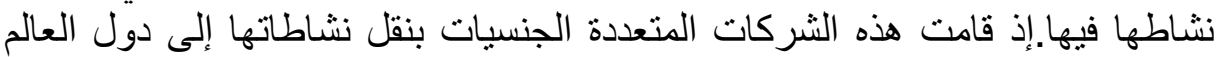

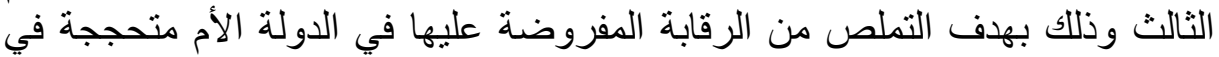

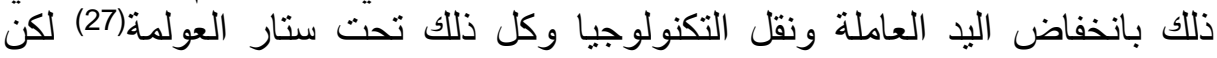

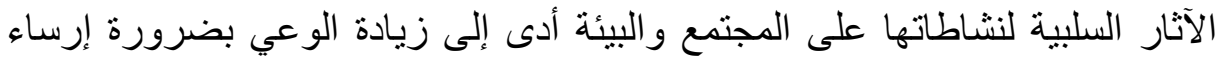

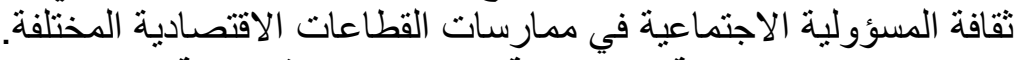

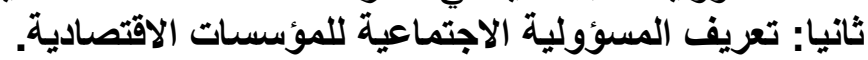

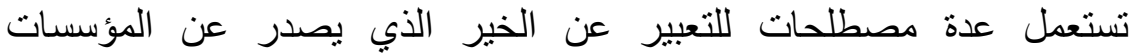

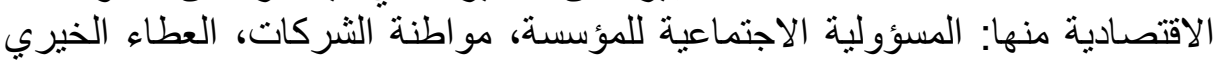

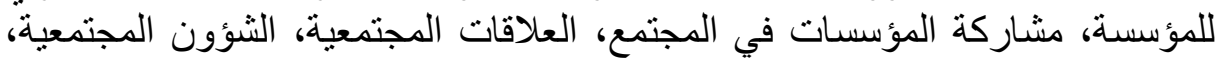

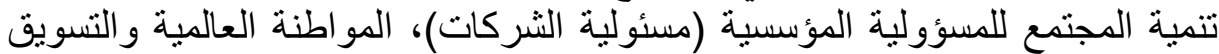

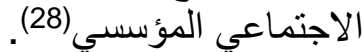

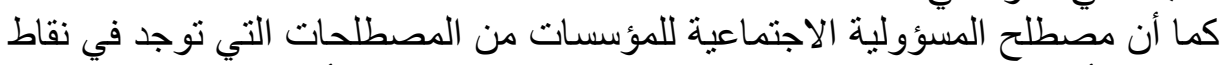

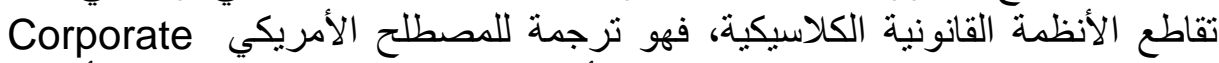
Social Responsibilty

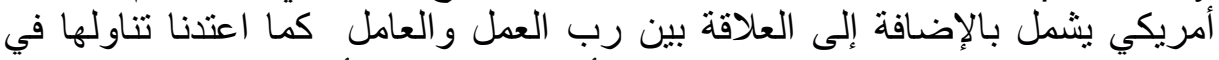

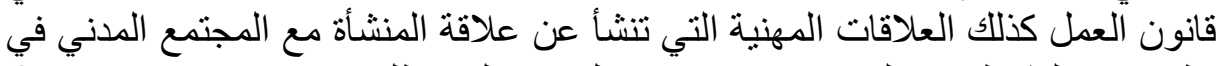

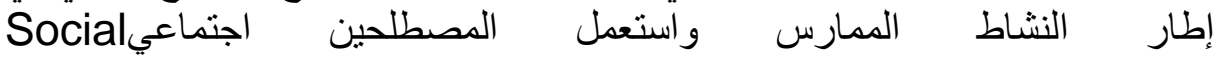

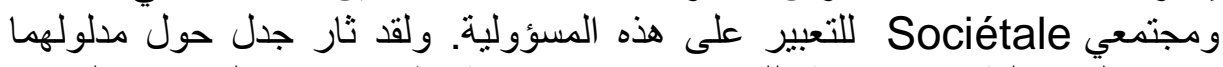

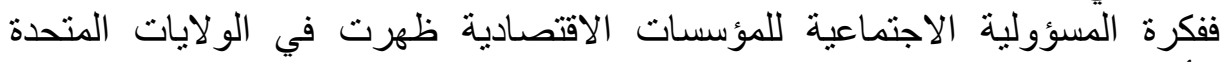
الأمريكية تحت مصطية الاجنماعة Corporate Social Responsibility Responsabilité Sociale Des Entreprises

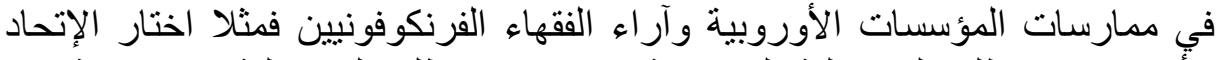

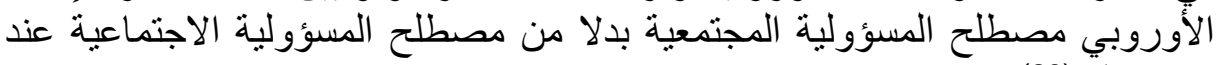
تعريفه لهاون(29).

وقد عرفها قاموس Business Dictionary B.N.E.T على أنها: " مبادرة طو عية

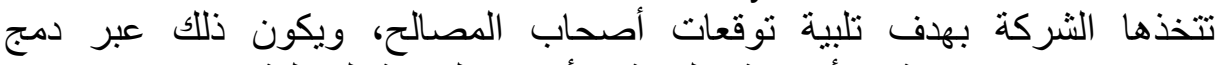

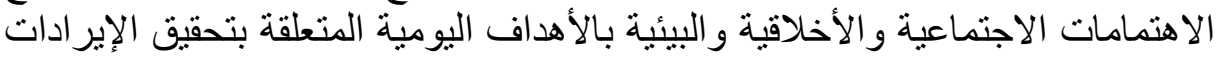

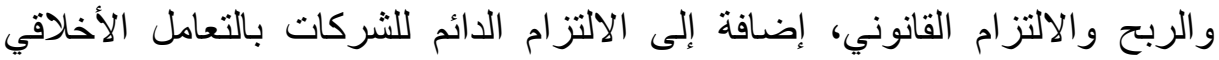

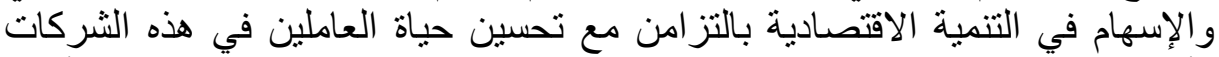

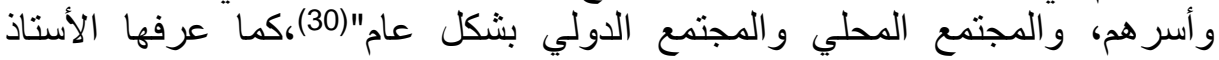

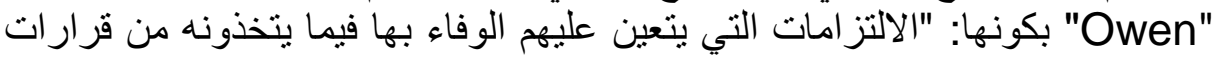

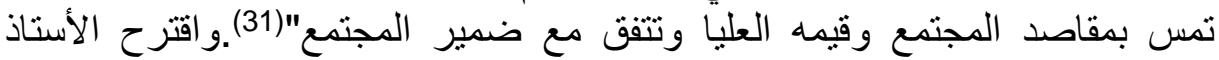

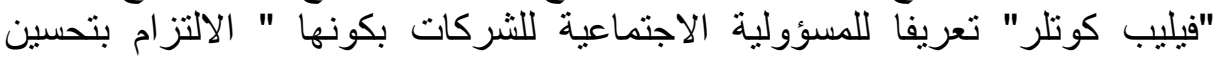

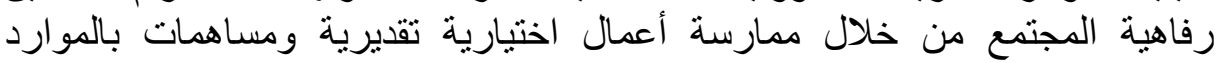
المؤسسية"(32).

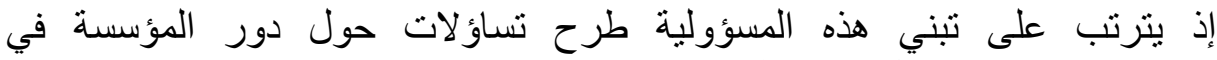

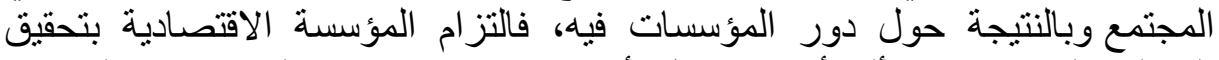

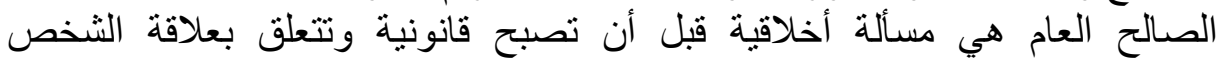

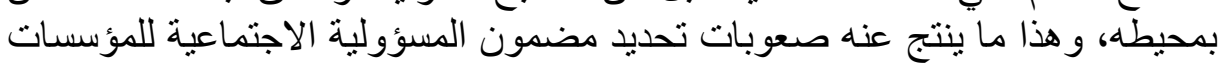

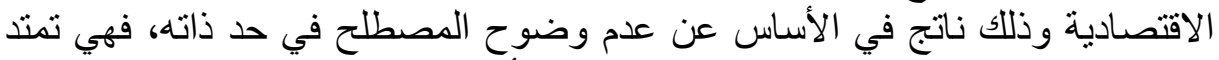

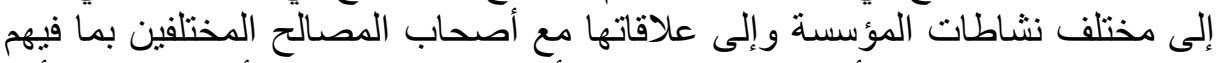

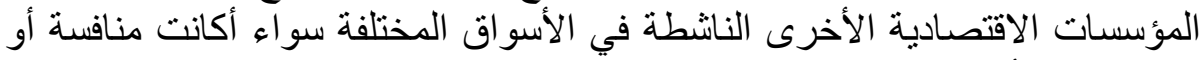

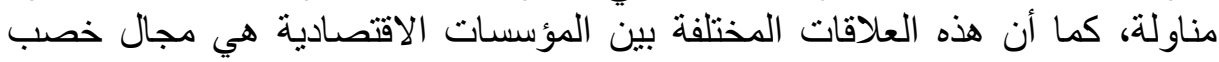


لترقية ممارسات المسؤولية الاجتماعية في سبيل تحقيق التتمية الاقتصادية،وهذه العلاقات المتبادلة هي موضوع العند العنصر الثناني من هذا في المقال.

المطلب الثاني: التأثير المتبادل بين المناولة والمسؤولية الاجتماعية للمؤسسات الاقتصادية.

بعد أن تطرقنا إلى مفهومي المناولة والمسؤولية الاجتماعية للمؤسسات

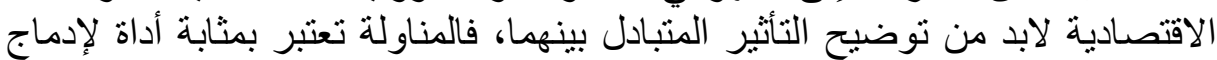

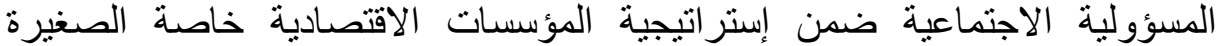

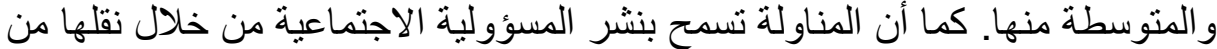

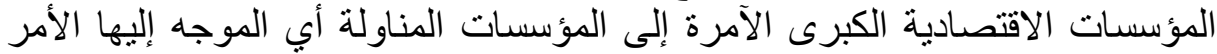

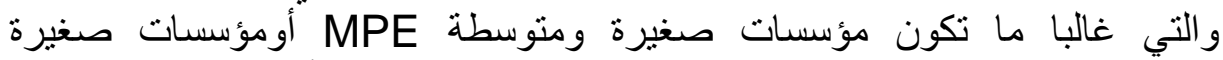
جدا TPE(مصغرة)حيث نظمت في التشريع الجزائري لأول مرة فئنة في قانون

المؤسسات الصغيرة و المتوسطة لسنة 2017المذكور سابقا.

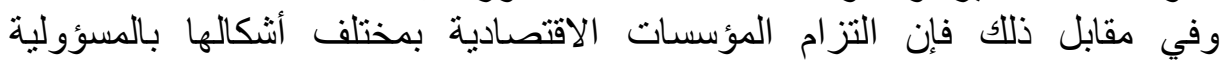
الاجتماعية في إطار المناولة يؤدي إلى تحسين مردوديتها وفعاليتها الاقتصادية، ويكسبها ميزة تتافسية ويقوي مكانتها في المجتمع ومحيطها ككل ورهذا لها ما يضمن

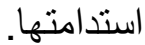

الفرع الأول: المناولة كأداة لإدراج المسؤولية الاجتماعية ضمن إستراتيجية المثؤسسات الاقتصادية.

تعتبر المناولة أداة لإدراج المسؤولية الاجتماعية ضمن استراتيجيات المؤسسات

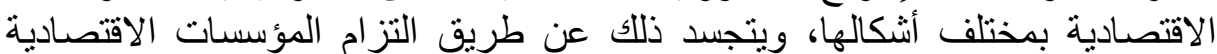

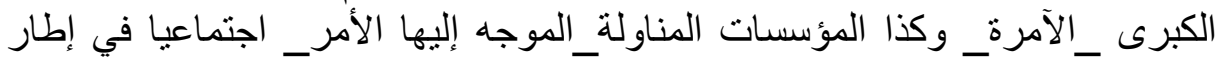

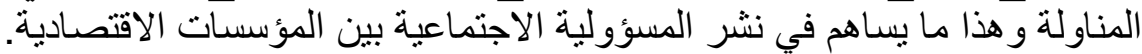

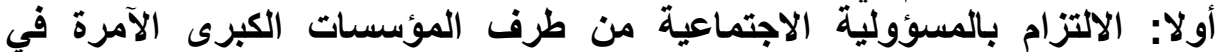

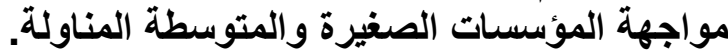

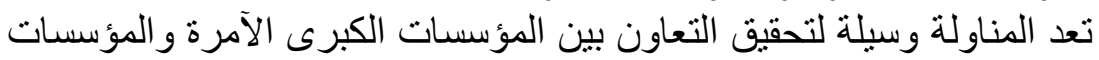

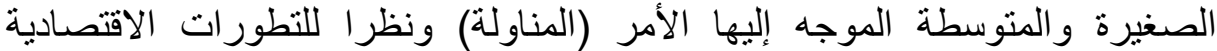

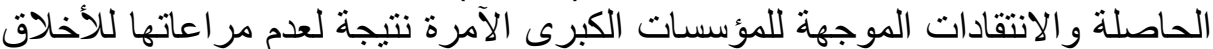

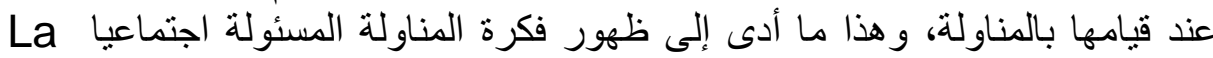

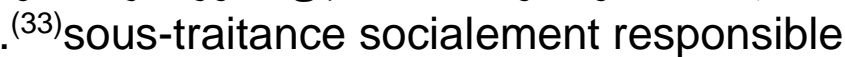

فالمؤسسات الكبرى وخاصة المتعددة الجنسيات التي تمارس نشاطاتها في

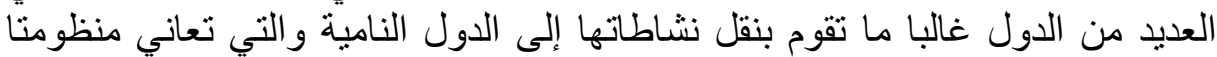

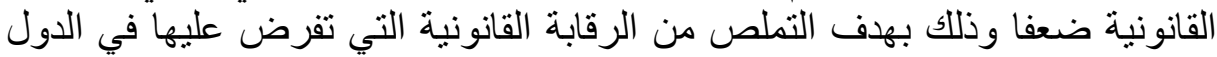

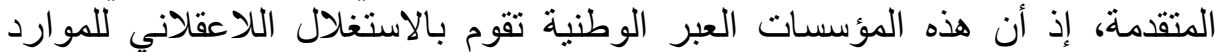

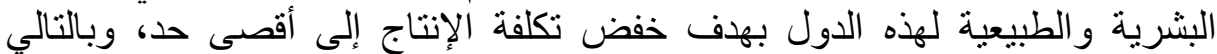

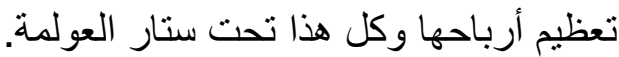

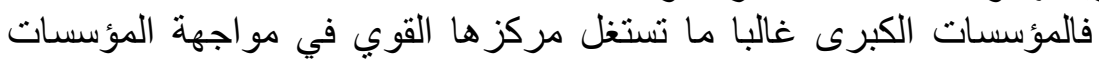

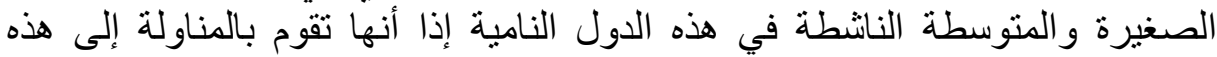

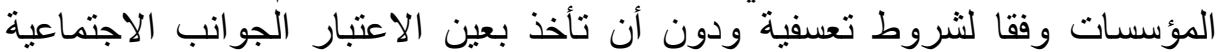

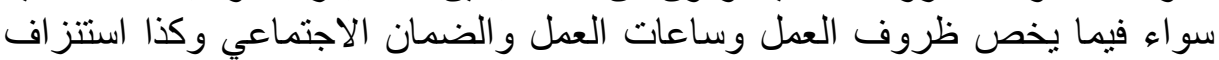
الموارد الطبيعية وتلويث البيئة فئنة

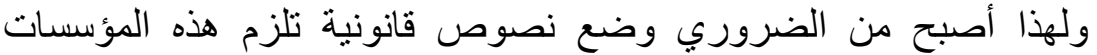

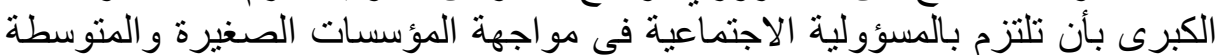




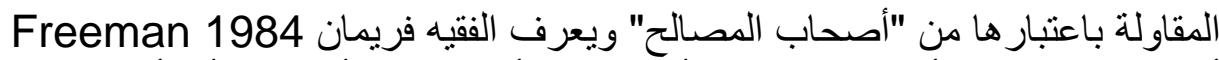

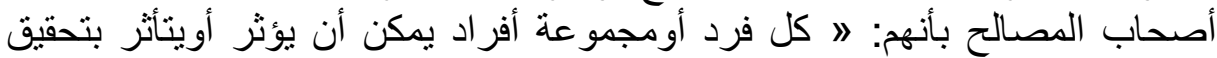
أهداف المؤسسةه(34).

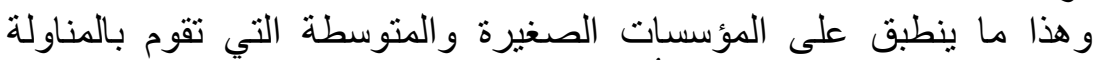

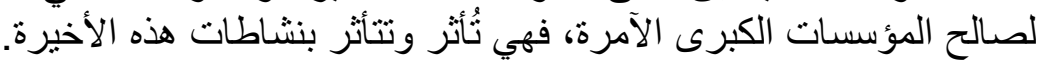

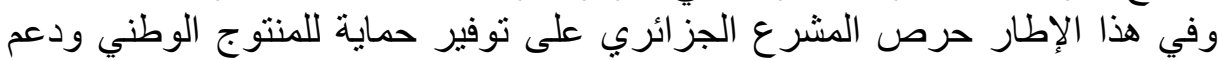

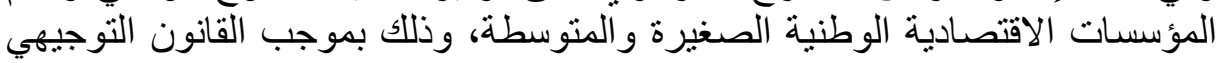

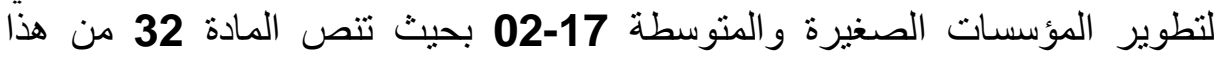

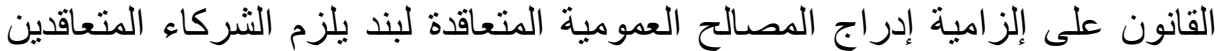

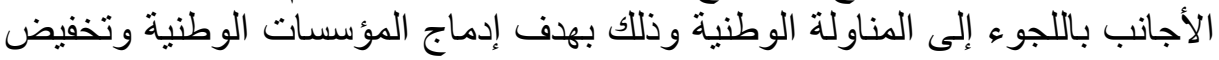

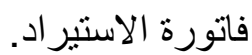

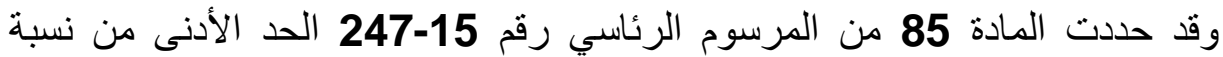
المناولة الوطنية بـ 30\% على الأقل من مبلغ الصفقة الإجمالي، كما منعت ذات التات المادة

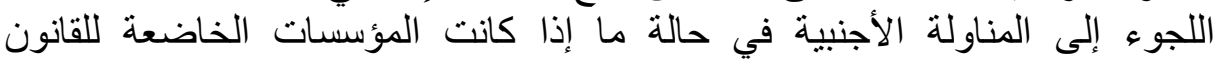

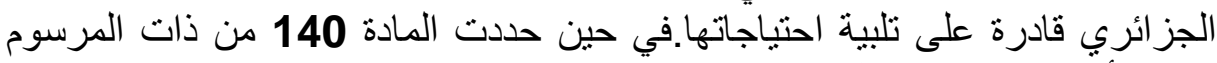

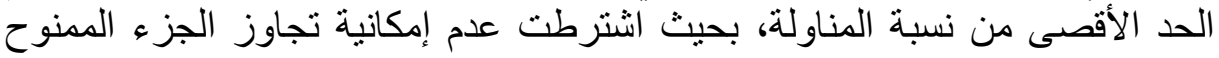

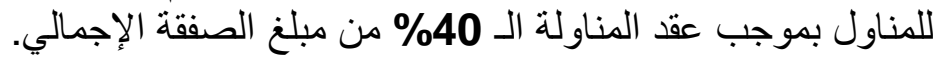

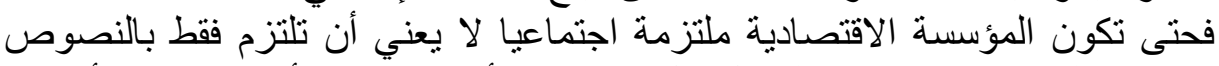

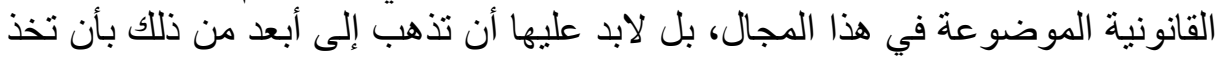

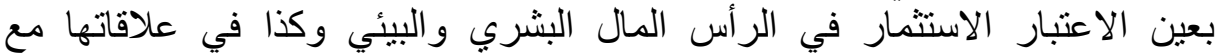

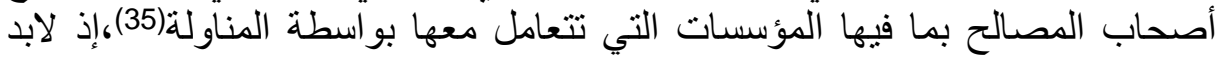

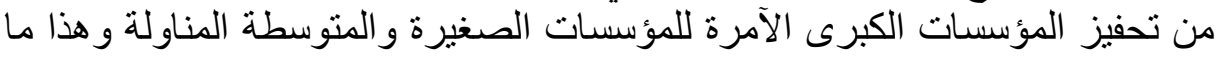

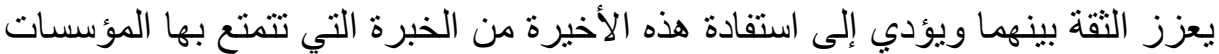

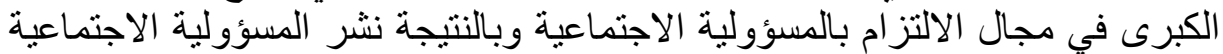

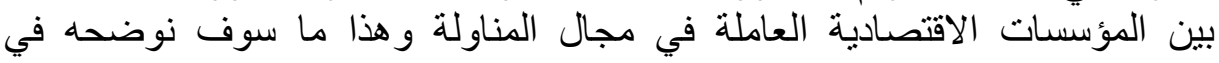

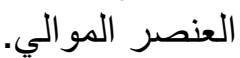
ثانيا:مساهمة المناولة في نشر المسؤولية المناولة الاجتماعية بين المؤسسات الكبرى الآمرة والمؤسسات الصغيرة والتمتوسطة المناولة فئنة المناولة.

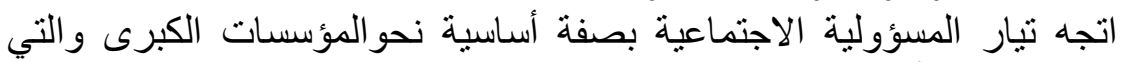

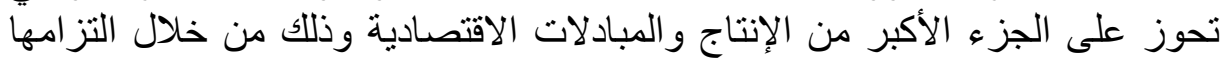

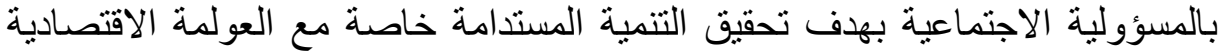

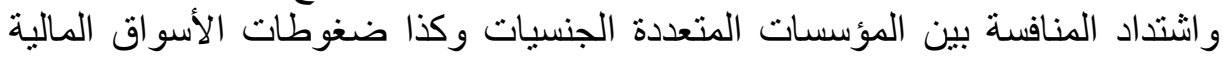

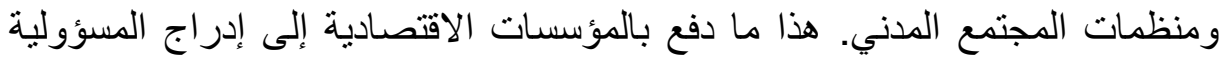

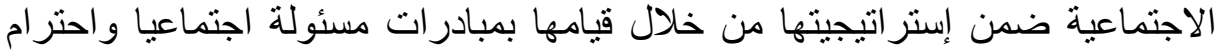
المبادئ الأساسية لحقوق الإنسان، وكذا تحسين ظروف التئن العمل وحماية البيئة(36).

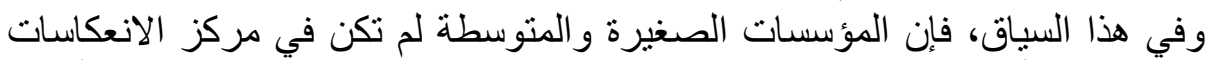

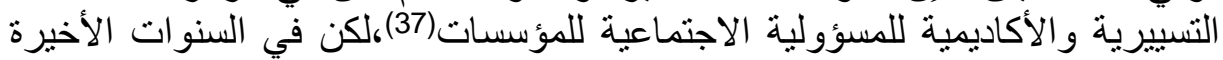

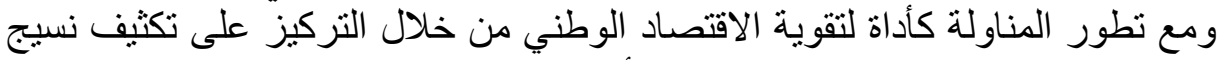

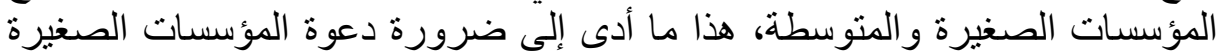

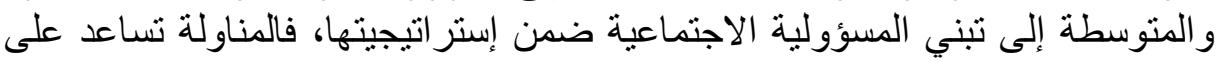

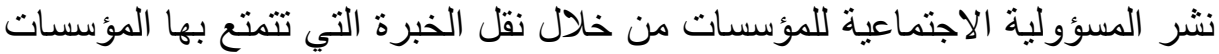

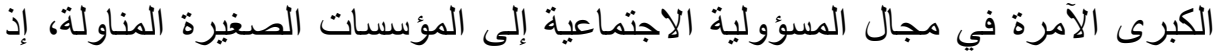

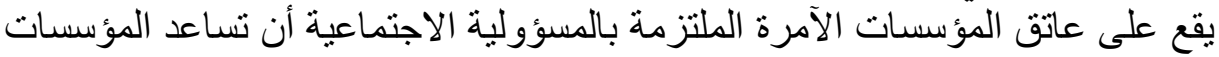

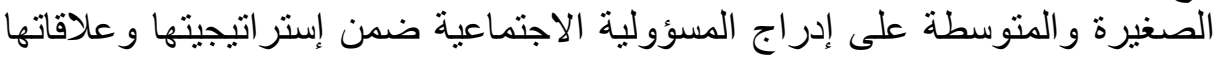
مع مختلف أصحاب المصالح. 
فداخل المؤسسات الصغيرة والمتوسطة PME و المؤسسات الصغيرة جدا تكون هناك علاقة مباشرة بين الملاك و المسيرين والعمال والمستهلكين المين

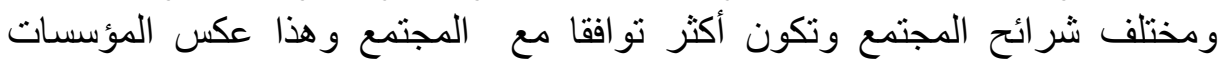

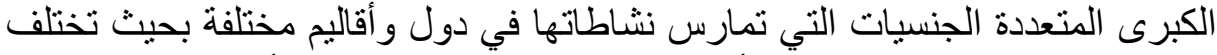

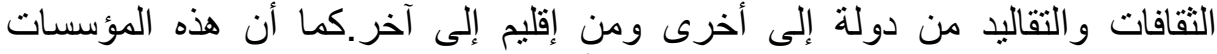

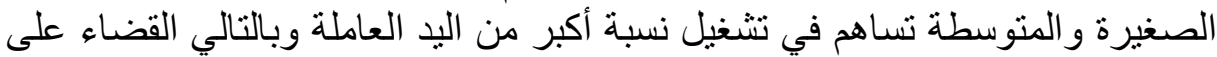

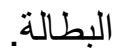

فعن طريق المناولة يمكن أن تقوم المؤسسات الكبرى بنقل التقنيات المتطورة

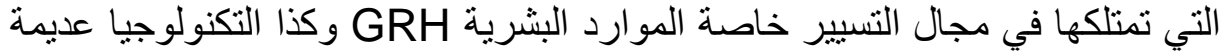

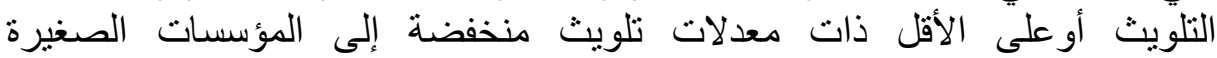
و المتوسطة PME و المؤسسات المتناهية الصغر المنات لئاولة TPE، وهذا ما يحقق حماية البيئة(38).

بالإضافة إلى ذلك فإن 80\% من المؤسسات الكبرى تقوم بنشر تقارير حول

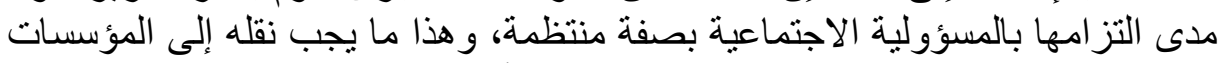

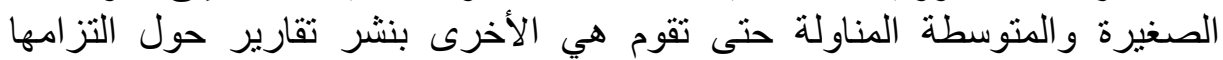

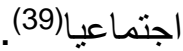

ومن جانب آخر ولدفع المؤسسات الصغيرة والمنوسطة PMEإلى الالتزام

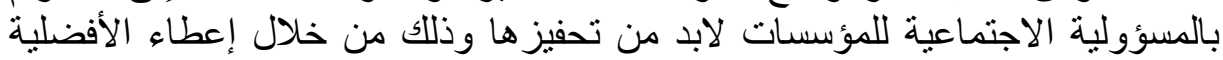

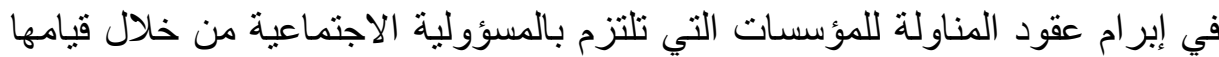

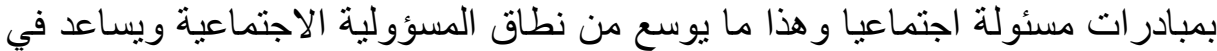

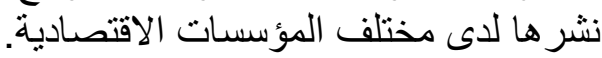
وفي الأخير نشير إلى أن التزام المؤسسات الكباتهبرى (الآمرة) بالمسؤولية

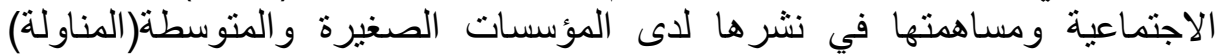

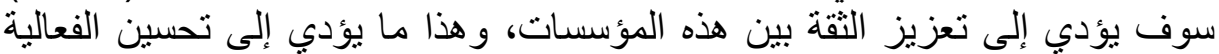

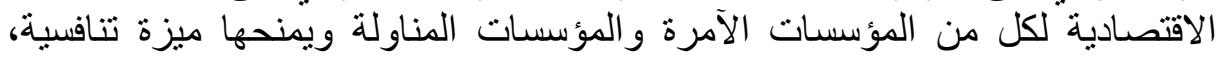

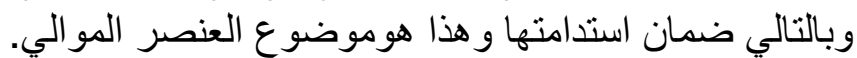

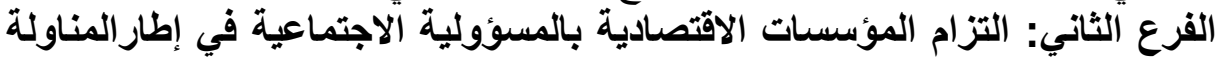
يمنحها العديدمن المزايا.

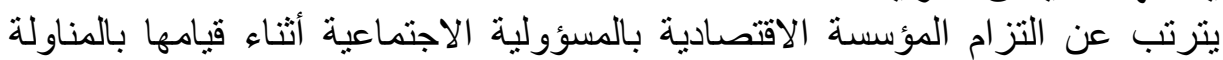

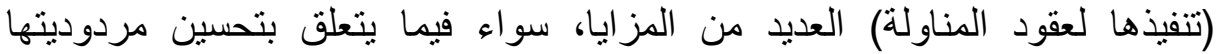

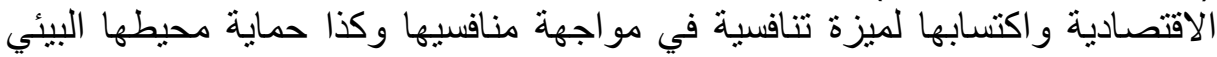

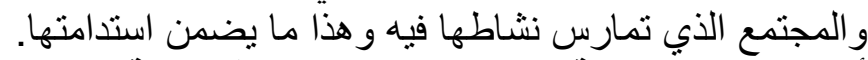
أولا: المزايا المتعلقة بتحسين مردوديتها الاقتصادية.

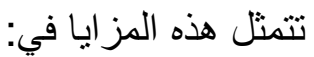

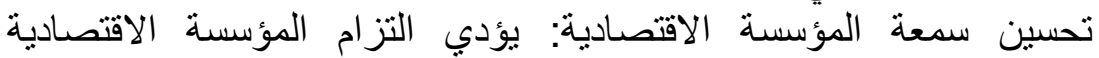

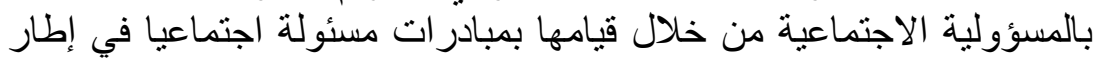

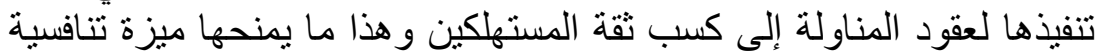

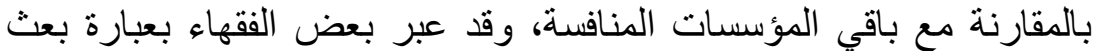

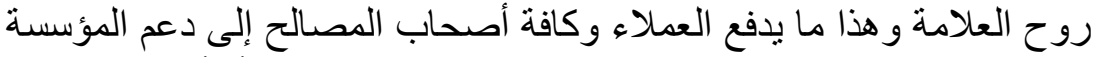

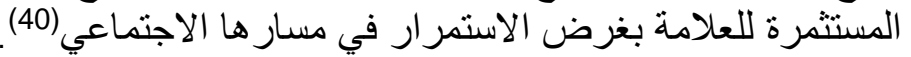

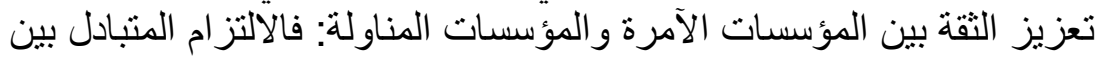

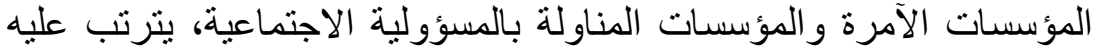

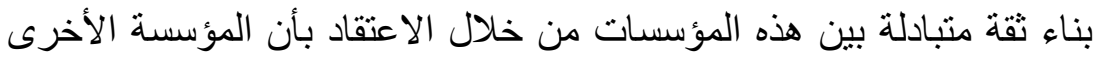


سوف تبذل جها كبير ا بهدف تحقيق نتائج إيجابية لكلا المؤسستين، وبالتالي المساهمة في تحقيق التعاون و التنسيق بينهما وهذا ما يؤدي إلى بناء علائ لاقيات

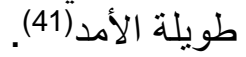

زيادة المبيعات وحصتها في السوق: فمع التطورات الاقتصادية الحاصلة

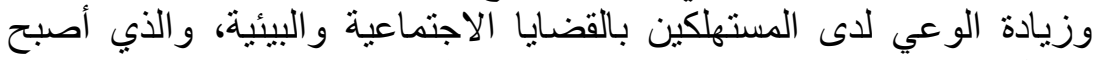

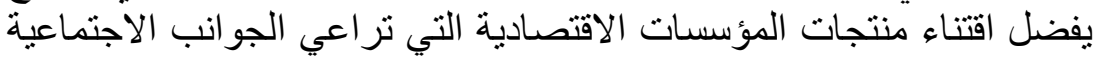

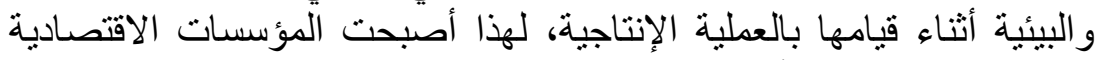

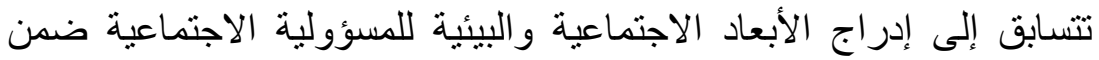

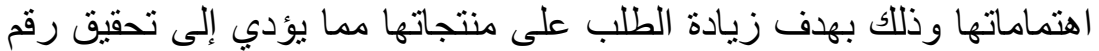

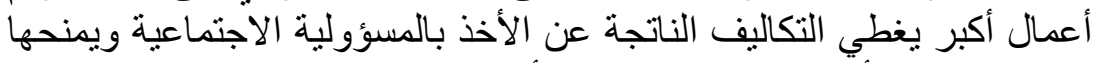

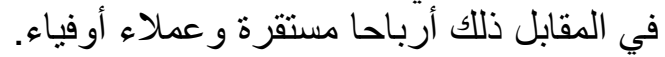

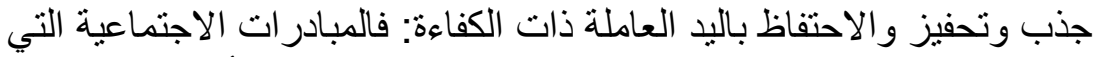

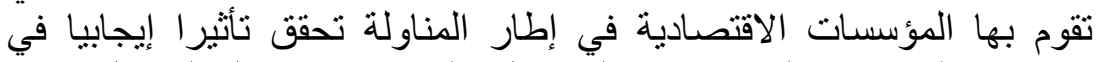

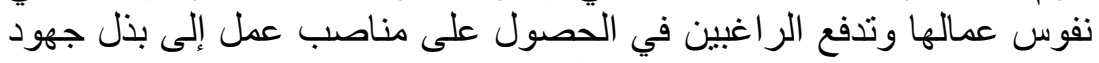

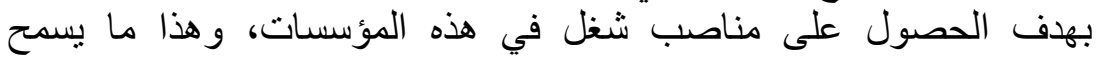
للمؤسسات الاقتصادية سواء الآمرة أوالمناولة فئل إلى جذب يد عاملة ذات كفاءة(42) زيادة القدرة على جلب رؤوس الأموال وتحسين وضعها المالي: إن التزام الإمات

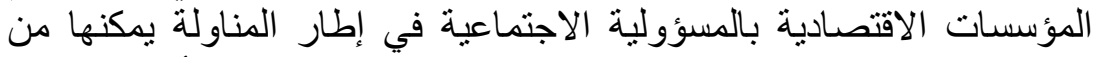

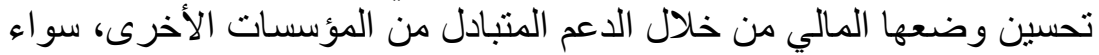

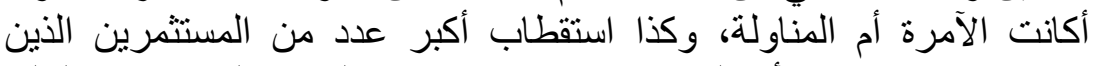

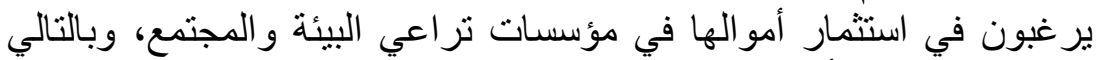

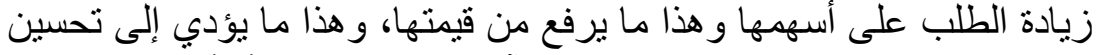

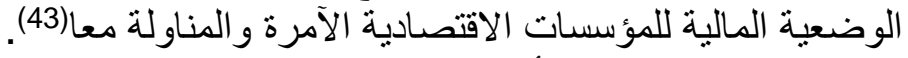

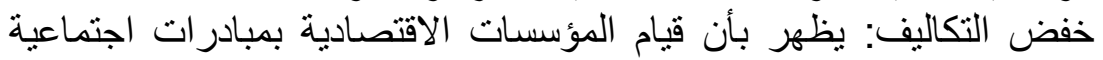

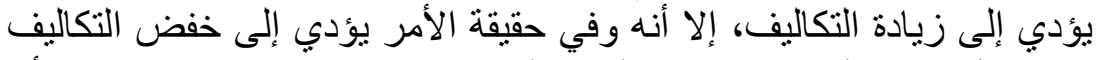

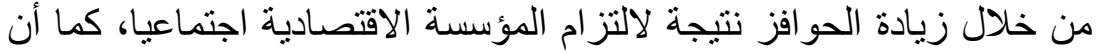

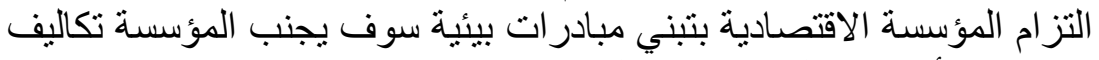

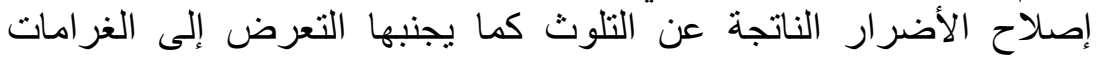

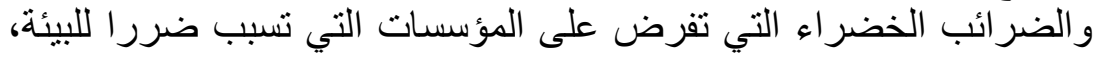

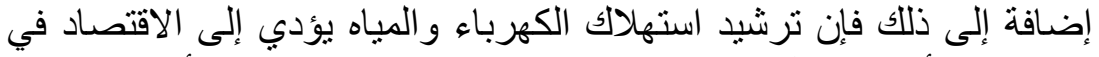

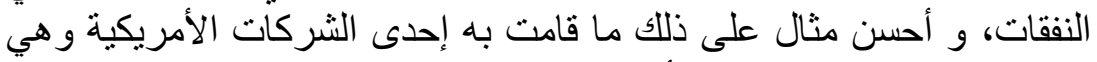

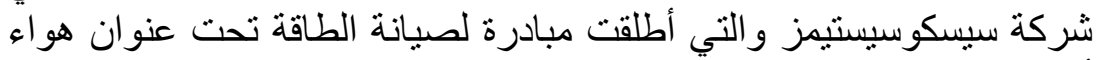

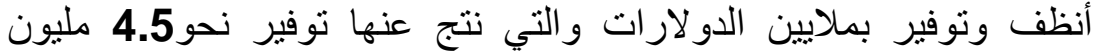

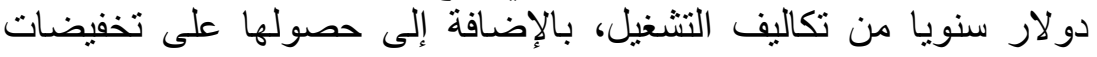
تقدر بـ 5.7 مليون دولار من من مورد الطاقة المحلي والمتمثل في شركة

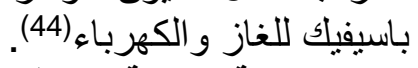

ثانيا: المزايا المتعلقة بحماية محيط المؤئسة

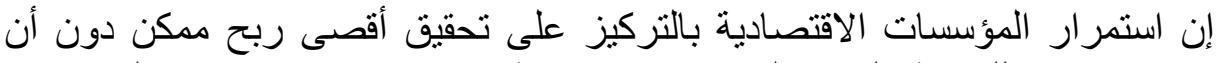

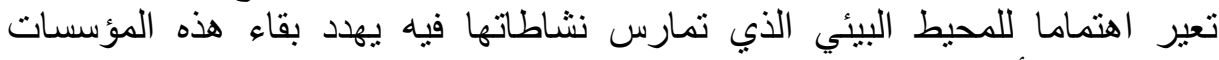

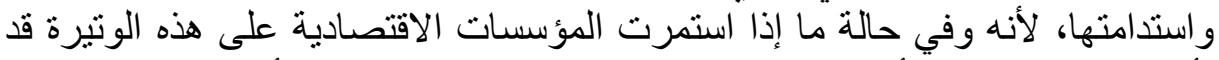

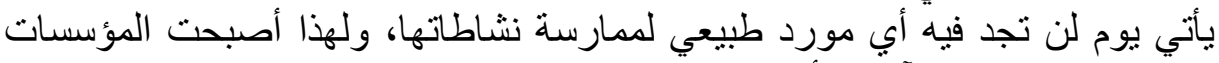

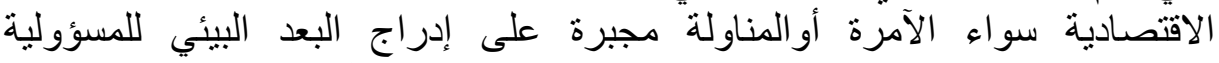

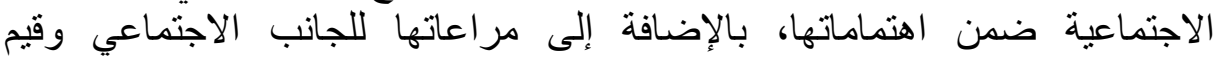

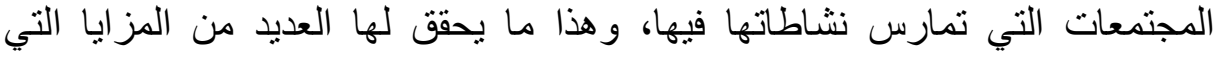


تضمن استدامتها و أهمها:

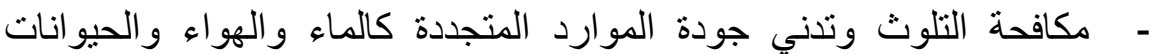

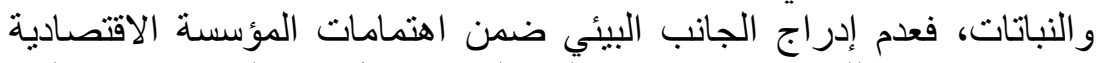

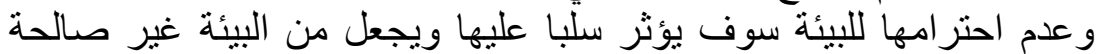

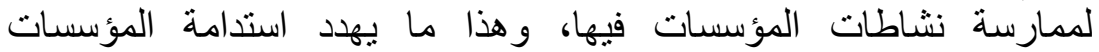
الاقتصادية(45).

فالمناولة تسمح بنقل وتبادل التكنولوجيا عديمة التلويث أو ذات معدلات التات تلويث

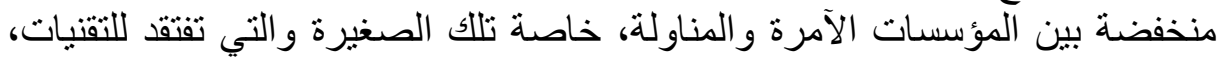

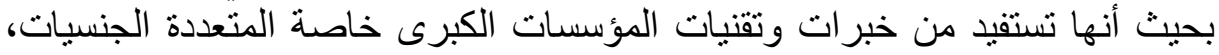
و هذا ما يساهم في حماية البيئة وبالتالي ضمان ونان استدامة ممارسة المؤسسات الاقتصادية لنشاطاتها.

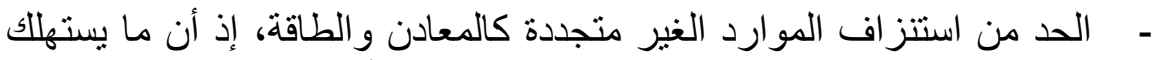

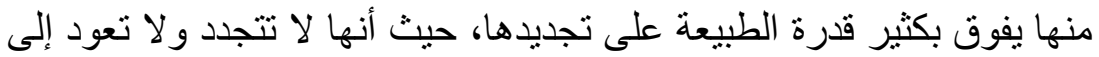

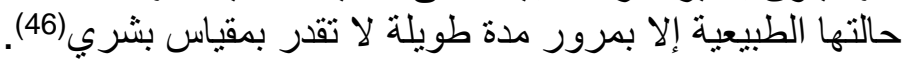

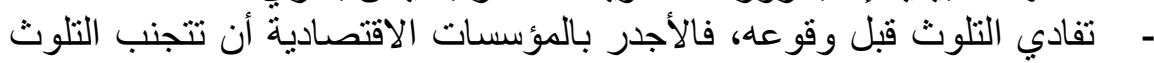

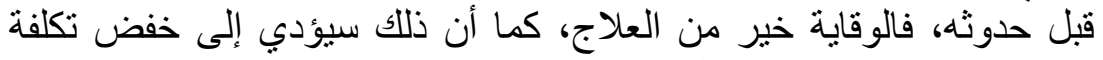

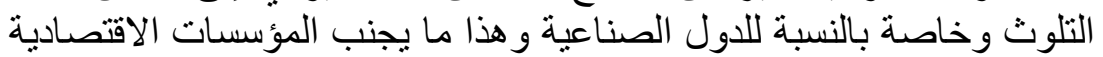
تحمل تكاليف العلاج وكذا الضر ائب و الرسوم البيئية(47).

تعد المؤسسات الاقتصادية بمختلف أشنكالها العمود الفقري لتحقيق التنمية

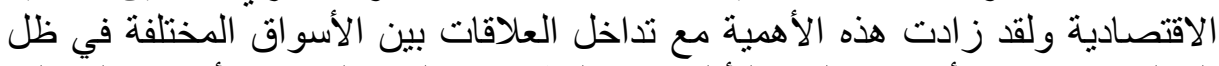

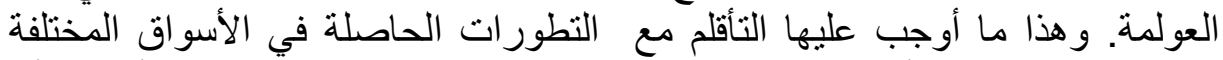

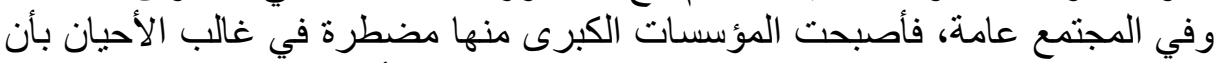

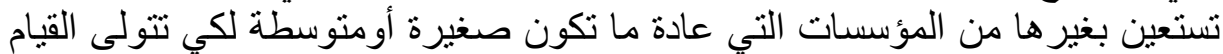

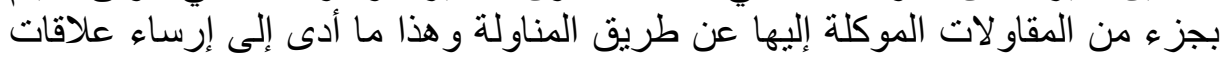

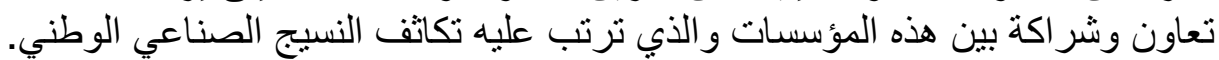

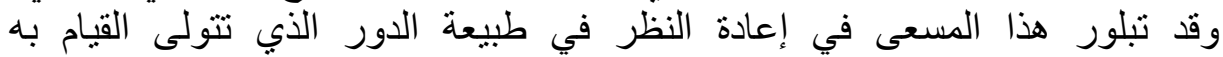

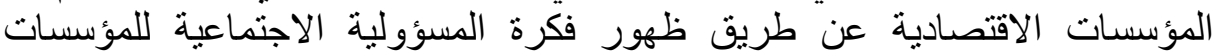

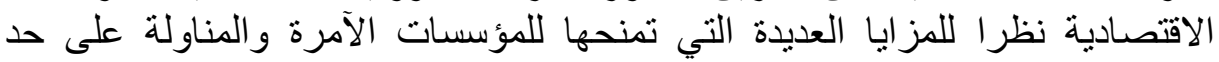

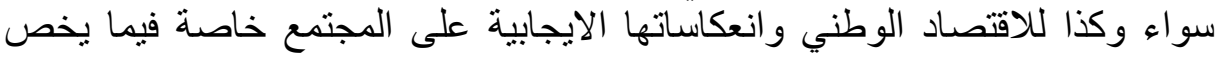

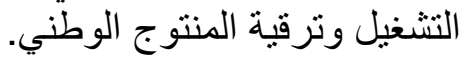

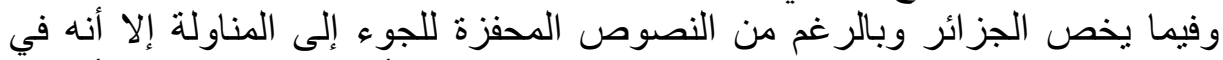

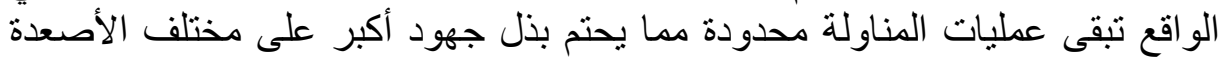

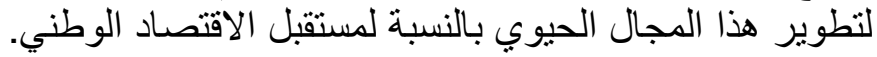




$$
\begin{aligned}
& \text { (1)-المرسوم الرئاسي رقم 96-438 المؤرخ في } 28 \text { نوفمبر } 1996 \text { المنضمن دستور } 1996 \text { - } 1996 \text { ج جر }
\end{aligned}
$$

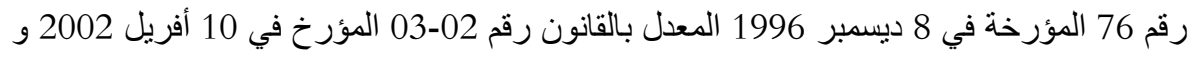

$$
\begin{aligned}
& \text { القانون 08-19 المؤرخ في } 15 \text { نوفمبر } 2008 \text { و و القانون 16-01 المؤرخ في } 6 \text { مارس }
\end{aligned}
$$

(2)-Samuel mercier, théorie des parties prenantes en management stratégique, une synthèse de la littérature, conférences de l'association international de management stratégique, 2001, université Laval, Québec, p3.

منوفر على الموقع :

https://mozartconsulting.sharepoint.com/Documents/theorie\%20de s\%20parties\%20prenantes\%20au\%20management\%20strategique. pdf

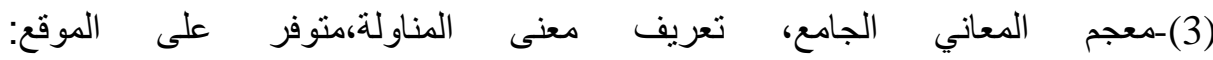

$$
\begin{aligned}
& \text { www.almarny.com/ar/dict/ar } \\
& \text { (4)- المرسوم الرئاسي رقم 15-247 المؤر خ في 16سبتمبر } 50 \text { الرئ } 2015 \text { المتعلق بالصفقات العمومية }
\end{aligned}
$$

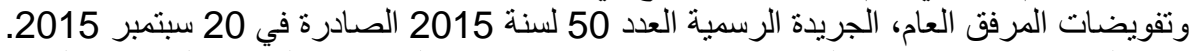

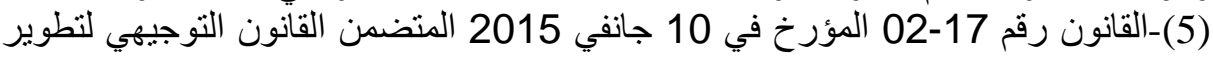

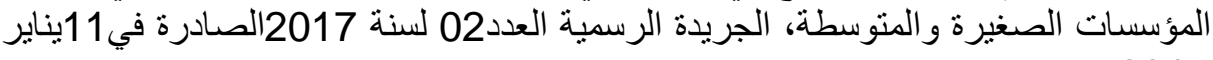

$$
\begin{aligned}
& \text {.2017 } \\
& \text { (6)-هذا القانون ما زال ساري المفعول وعدل عدة مرات في سنوات }
\end{aligned}
$$

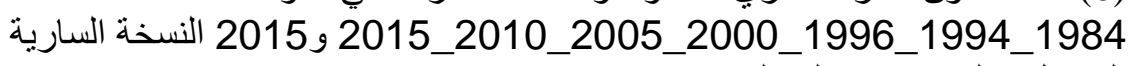

$$
\begin{aligned}
& \text { المفعول حاليا منوفرة على الموقع }
\end{aligned}
$$

https://www.legifrance.gouv.fr/affichTexte.do?cidTexte=JORFTEXT000 000889241

Article1 « Au sens de la présente loi, la sous-traitance est l'opération par laquelle un entrepreneur confie par un sous-traité, et sous sa responsabilité, à une autre personne appelée sous-traitant l'exécution de tout ou partie du contrat d'entreprise ou d'une partie du marché public conclu avec le maître de l'ouvrage ».

)(7- Dominique CASIN, Sous-traitance responsable et création de valeur, Université Nancy-Metz, P4.

« l'opération par laquelle, une entreprise (donneur d'ordre) confie à une autre (preneur d'ordre ou sous-traitant) le soin d'exécuter pour elle et selon un certain cahier des charges préétabli une partie des actes de production ou de service dont elle conserve la responsabilité économique final » .

(8)- Bernard BOUBLI, Contrat d'entreprise, répertoire Dalloz, Paris, droit civile, 2003, P41.

(9)-IBID, P43.

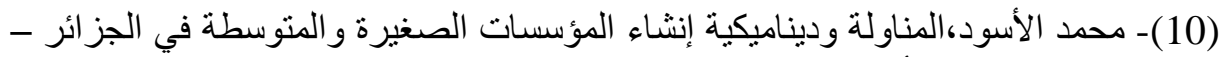

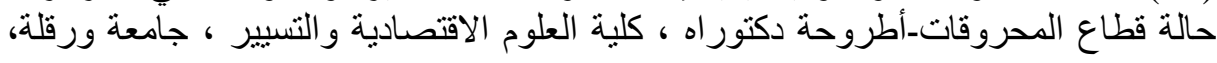

https://bu.univ-ouargla.dz/Theses\%20DOCTORAT/Mohammed-elasoid-

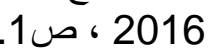
Doctorat.pdf

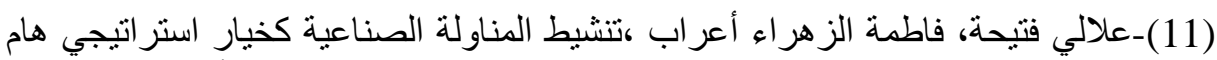

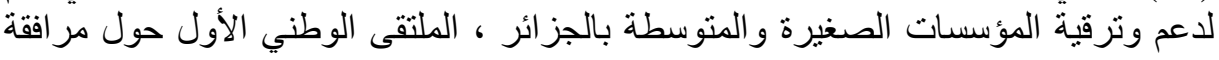


المؤسسات الصغيرة و المتوسطة ، كلية العلوم الاقتصادية والتسيير، جامعة ورقلة.متوفر على :-لى https://dspace.univ-: ouargla.dz/jspui/bitstream/123456789/2623/1/34.pdf تم الاطلاع عليه بتاريخ : 15-018-2018.

(12)- القانون رقم 25-88 الصادر في 12 يوليو1988 المتعلق بتوجيه الاستثمارات

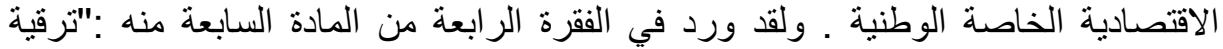
نشاطات المقاولة من الباطن و الصيانة قصد زيادة فعالية القدر ات الإنتاجية الوطنية ل..."

(13)-أ. صيد ماجد، د. رقايقية فاطمة الزهراء " المناولة الاقتصادية كمدخل لتعزيز الميزة

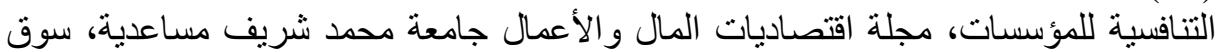

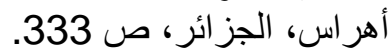

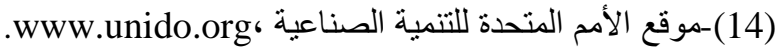
(15)- جريدة البلاد، 2017-10-24 ، الكاتب سعاد الكاد بوربيع، تحت عنوان " توسيع نظام التشغيل

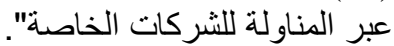

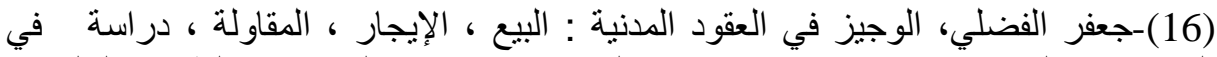
النصوص القانونية معززة بالاجتهادات القضائية ، دار الثية الثقافة ، الطبعة الثالثة ، .410.2014

(17)- Bernard BOUBLI, Op-Cit, P48.

(18)- نص المادة 307 من القانون المدني \ا ينقضي الالتزام إذا أثبت المدين أن الوفاء به

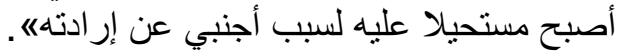

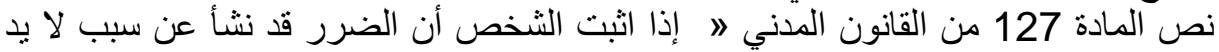

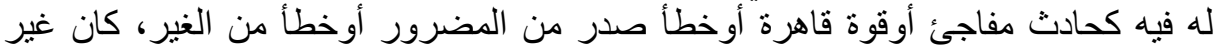

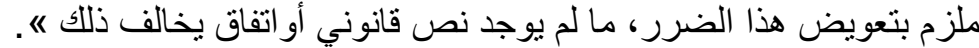

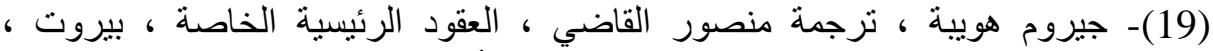

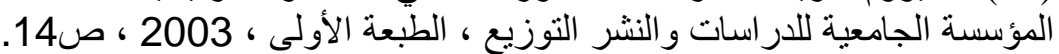

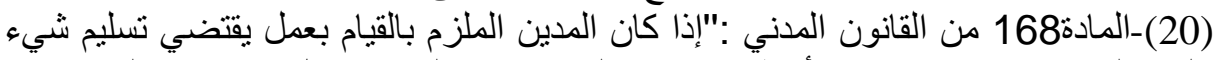

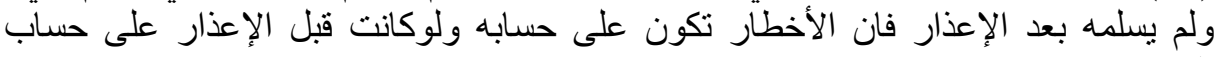

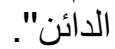

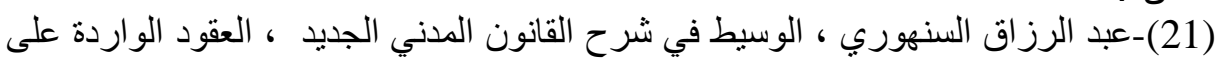

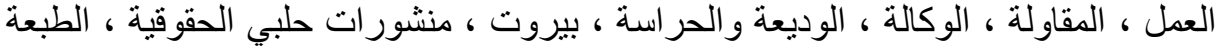

(22)- Bernard BOUBLI, Op-Cit, P 50.

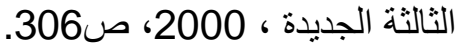

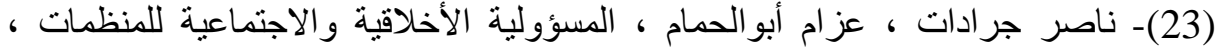
الأردن ، دار إثراء للنشر و التوزيع، الطبعة الأولى، 2013، 2013، الصول 12.

(24)- François Lépineux et autres, la RSE la responsabilité sociale des entreprises, Paris DUNOD 2012, P28

(25)- François Lépineux et autres Op-Cit, P29, 30.

(26)-Isabelle Cadet, responsabilité sociale de l'entreprise (RSE), responsabilités éthiques et utopies, les fondements normatifs de la RSE, étude de la place du droit dans les organisations, thèse de doctorat, école doctorale abbé Grégoire, 22 janvier 2014, P130

(27)- « la société doit la subsistance aux citoyens malheureux soit en leur procurant du travail , soit en assurent les moyens d'exister à ceux qui sont hors état de travaille ».

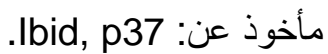

(28)- فيليب كوتلر، نانسي لي، ترجمة علا أحمد إصلاح، المسؤولية الاجتماعية للشركات، الطاتي، الدار الدولية للاستشار ات الثنقافية، القاهرة، الطبعة الأولى، 2011، 201ا، صل 7. 


$$
\text { (29)- ناصر جرادات، عز ام أبو الحمام، المرجع السابق، ص } 217 .
$$

(30) - Isabelle Cadet, Op-Cit. P130.

(31)- R.S.E une dimension sociale ou sociétale.

منوفر على الموقع: www.kritsalmon.com ، ند الإطلاع عليه بتاريخ : 20 مارس 2018.

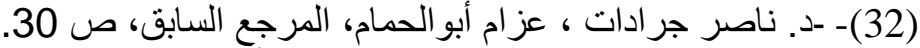

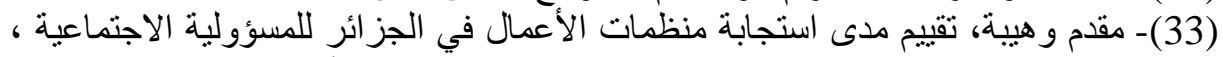

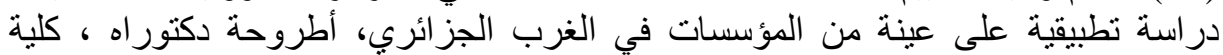

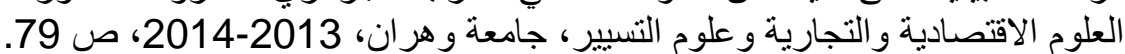

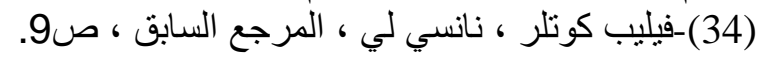

(35)- Dominique CASIN, Op-Cit, P2.

(36)-Nathalie Ravidat, Christophe Faurie , sous la direction de Jean-Jacques PLUCHART et Odile UZAN responsabilité sociale de l'entreprise Ma éditions, Paris, 2017, P;53. " tout groupe ou individu qui influence ou peut être influencé par la réalisation des objectifs de l’Entreprise ».

(37) -Dominique CASIN, Op-Cit, P3.

«Être socialement responsable signifie non seulement satisfaire aux obligations juridique applicable mais aller ou delà et investir davantage dans la capital humain l'environnement et la relation avec les parties prenantes ».

(38)-Jean-Marie COURENT, RSE et développement durable en PME, Comprendre pour agir, DeBoeck Bruxelles, Belgique, 1er édition, 2012, P 17. (39)-IBID, P18

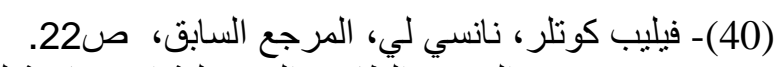

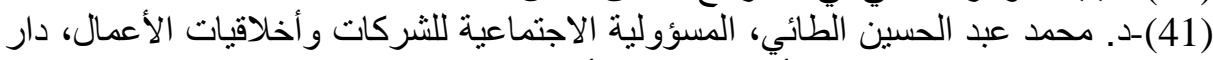

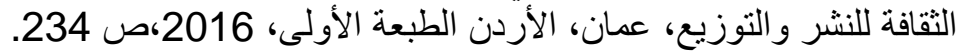

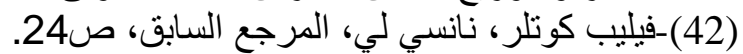

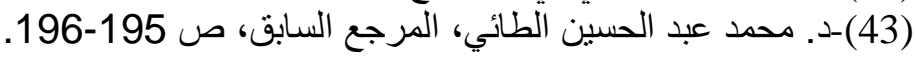

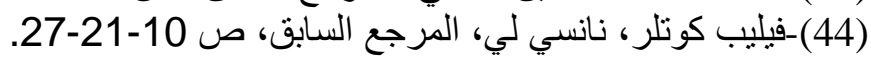

(45)- Michel Coster, entrepreneuriat, Pearson édition, Paris, France, 2009, P345-346.

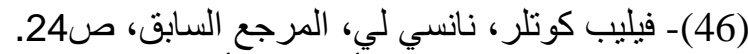

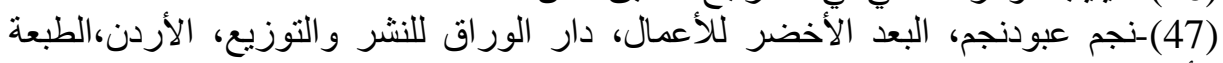

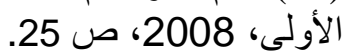

